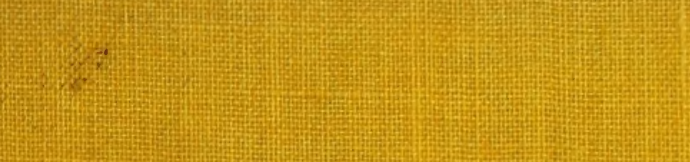

-

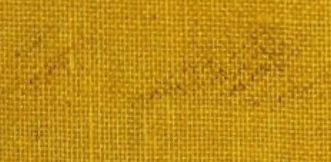

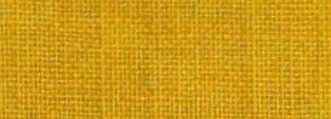

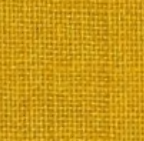

(i)

(2)

(t) +1.

(4)

(texte

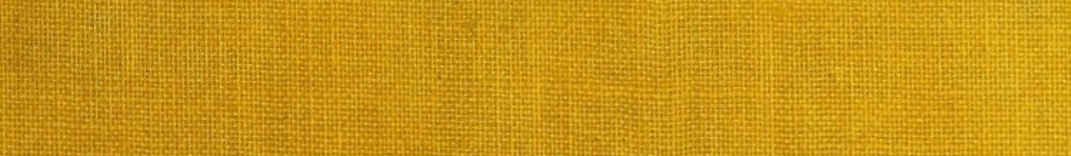

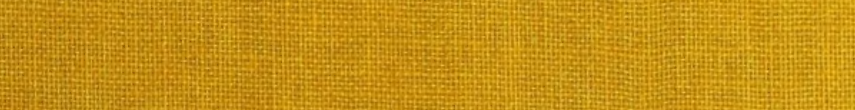

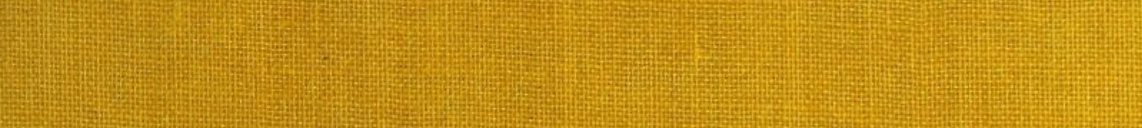

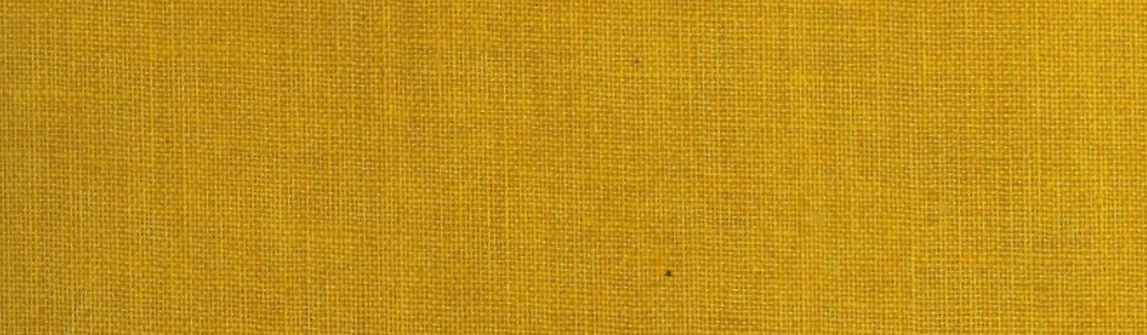

if

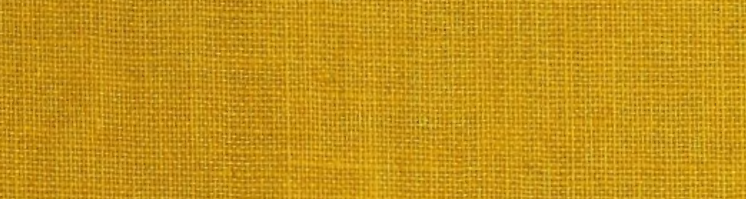

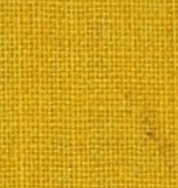

-

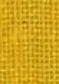

$+4+1$

$+\sin ^{2}$

$+2+5$

(c)

(i)

$+\frac{+5}{+i+3}$

+4.4.

(2)

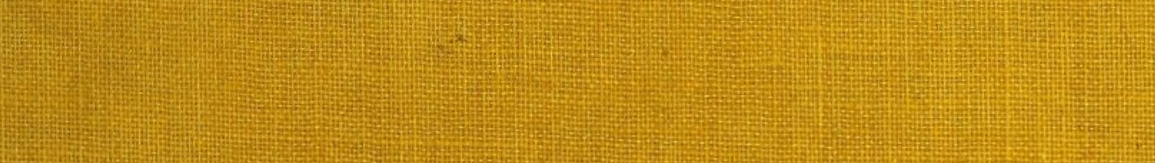

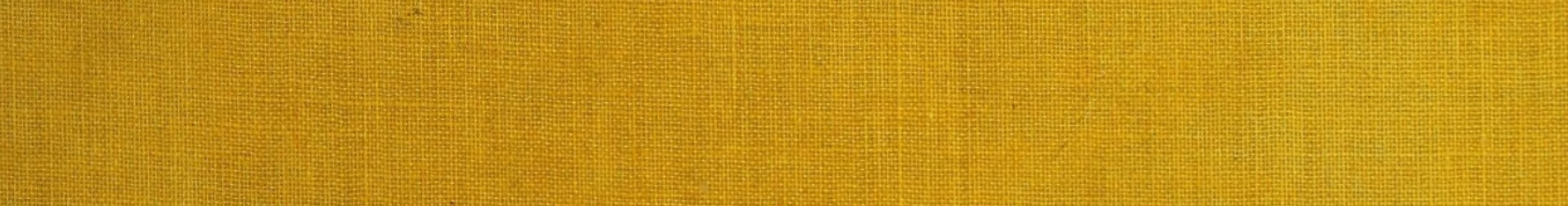

(a)

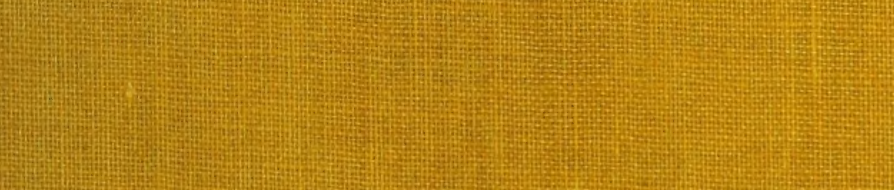
(2) 


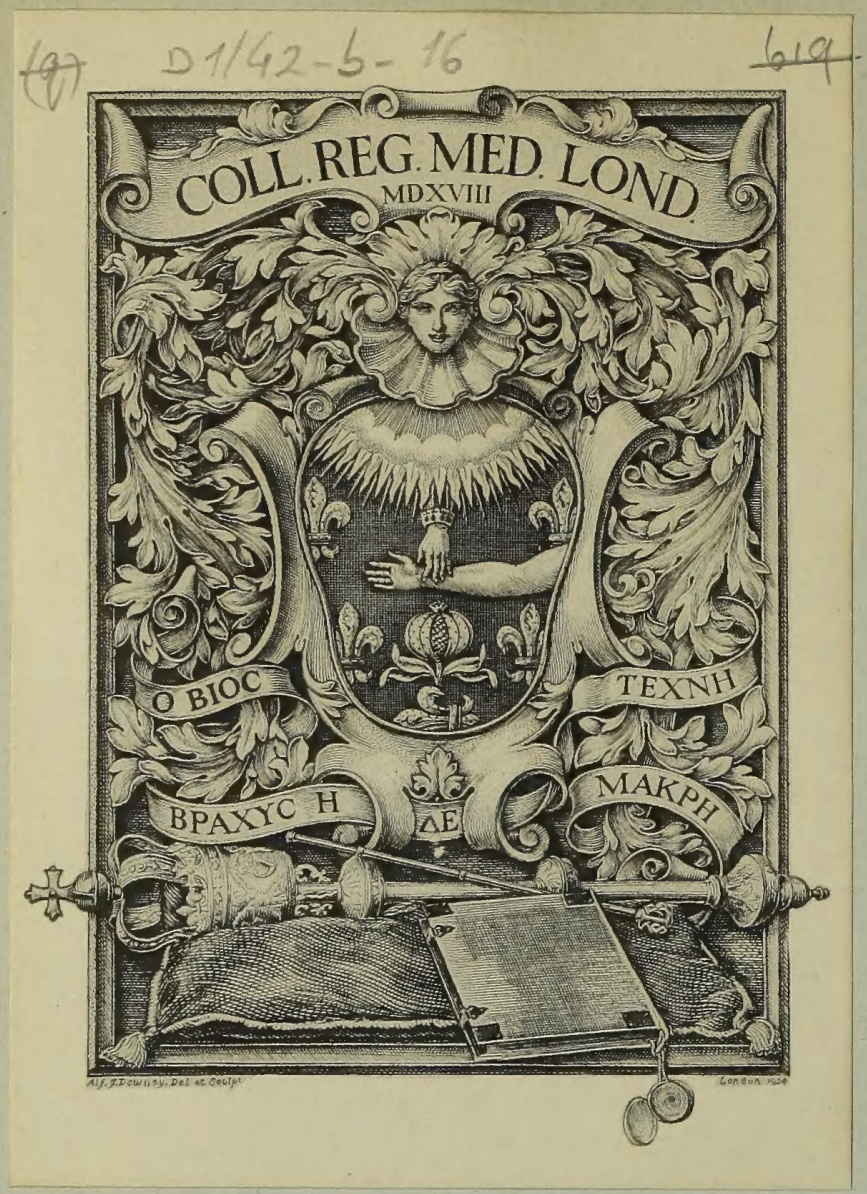



6 
Digitized by the Internet Archive in 2016 with funding from Jisc and Wellcome Library 



\section{A PRACTICAL MEMOIR}

ON THE

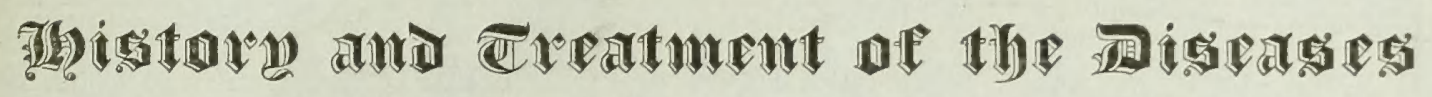

of

\section{T H E C A M E L,}

WITH INSTRUCTIONS FOR PRESERVING ITS EFFICIENCY AS AN ANIMAL OF TRANSPORT,

AND

A GENERAL OUTLINE

\section{O F I T S N A T O M Y;}

ALSO,

\section{AN ACCOUNT OF THE MEDICINES}

USED IN THE CURE OF ITS DISEASES;

DRAWN UP

By W. G I L C H R I S T, EsQ.
Assistant Surgeon, Pub. Catt. Depot,

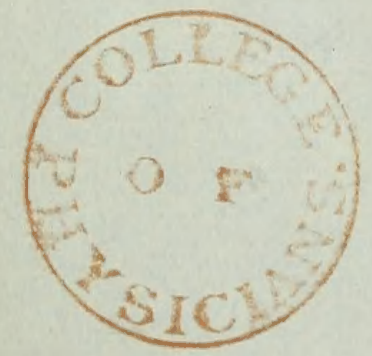

\section{HOONSOOR.}

C A L C U T T A :

G. H. HUTTMANN, BENGAL MILITARY ORPHAN PRESS. 


\begin{tabular}{|l|l|}
\hline ROYAL COLLEGE OF PHYSICIANS \\
LIBRARY \\
\hline CLASS & 619 \\
\hline ACCN. & 20884 \\
\hline SOURCE & \\
\hline DATE & \\
\hline
\end{tabular}




\section{PREFATORY REMARIS.}

This Memoir is not forwarded as professing to contain a complete treatise of instruction on the subject of which it treats. It is drawn up with the object of complying, to the best of my ability, in reference to the opportunities for the investigation of the diseases of the Camel, with the requisition of the Honorable the Court of Directors as set forth in the following documents, forwarded to me for my information and guidance.

\section{MILITARY DEPARTMENT.}

19 and 20 , forward letters from the Commissary General, submitting explanation in reference to Court's paras. on the expediency of a Veterinary Surgeon being appointed to the Public Cattle Depôt, in Mysore, with copies of other papers connected with the subject.
Extract from a letter from the Honorable the Court of Directors, dated 8th January, tion 5th May, 1840. 1840.

Para. 20. We concur with the Commissary General in considering the Report furnished by Assistant Surgeon Gilchrist, on the diseases of Cattle, to be very creditable to his zeal and industry, and that whilst the Depôt has the benefit of his service, the appointment of a Veterinary Surgeon to it is quite unnecessary. We would suggest that copies of his Reports should be furnished to Medical Officers in charge of Studs in Bengal and Bombay, and that the results of their experience should be communicated to Mr. Gilchrist. municated to the Commissary General in reference to an extract from the Minutes of Consultation, No. 3191, under date the 25th of September, 1838 , and he will be instructed to forward copies (two of each) for transmission to Bengal and Bomdate been received from the Medical Officer attle Depôt in Mysore, on the diseases of Cattle,

This para. will be combay respectively, of all $\mathrm{Re}$. ports which have up to this tached to the Public Catand to forward for the same purpose two copies of such Reports as may hereafter be received from that Officer.

True Extracts, 
In drawing up this Memoir, I have observed the same plan and had in view the same object as in drawing up the Memoir on the diseases of the Elephant, forwarded to Government in 1840 , and which I am gratified to learn has received the favourable notice of the Right Honorable the Governor in Council of Fort Saint George, and of the Honorable the Court of Directors at Home. In order, therefore, to convey an idea of the design of arrangement of this Memoir, the prefatory remarks of that on the Elephant are here introduced, with the simple alteration, substituting for the word Elephant that of Camel.

The object of this Memoir is to communicate the result of my researches into the History and Treatment of the Diseases of the Camel, and to convey such other information, which has come into my possession during my enquiries as will, it is hoped, prove useful in preserving the efficiency of that useful animal.

The design of the Memoir being purely practical, all questions relative to the animal not connected with its efficiency in regard to the use made of it in the Public Service, however interesting in themselves, are carefully excluded. Considered only in regard to being employed in the Public Service as a means of transport, \&c., such concise instructions are given for the preservation of its efficiency, and the treatment of its diseases, as will admit of easy reference, and convey the desired information. During peace when time and facilities exist to recruit this Department of the Public Cattle as occasions arise, the individual value of the animal is, to an extensive Government like that of British India, of little comparative amount. But opposite conditions exist in regard to its value during the progress of Military operations when circumstances render difficult fresh re-inforcement to meet the decreasing number, or efficiency, in those employed. The preservation of the efficiency of individual animals, during active service, more especially when employed beyond the Frontier, being an object of paramount importance, I have steadily kept in view while drawing up this Memoir, the communicating whatever had occurred to me as likely to prove conducive to that important end, so that those in whose hands is entrusted the superintending charge of the Public Cattle, will, it is hoped, find in it information which will assist them in the discharge of their important duties connected with the subject herein discussed.

In reference to the Extract from Minutes of Consultation of Government, given at the commencement of these prefatory remarks-it will give me much pleasure to be put in possession of the exchange Reports, respectively of the Elephant and of the Camel, from the Bengal Presidency. With respect to this exchange it gives me pleasure that $I$ have as regards Reports on the two animals just named, been enabled to take the initiative. 


\section{PART F I R S T.}

\section{HISTORY AND TREATMENT OF DISEASES OF TUE CAMEL.}

\section{DISEASES OF THE HEAD.}

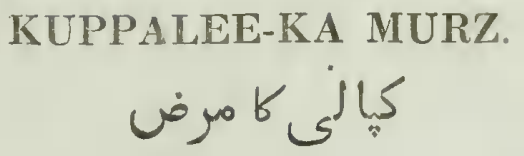

History.- The term is applied to an inflammatory affection situated in some part of the head which if left uncontrouled proceeds to ulceration, and usually terminates in the death of the animal. The most common seat of the affection is the soft parts in the orbit or the eye-ball itself.

The disease commences with tremors over body: about $2 d$ day thereafter the neck becomes stiff throughout its length, and after the lapse of other 24 hours a tumour hard and prominent, and about the size of a small hen's egg, appears on top of head; if that be the immediate seat of the malady, or if the orbit or eye-ball is its site, then eye-lids swell, there is much watery discharge. As the disease progresses the eye-lids are turned outwards, the eye-ball swells and inflames. If active measures are not resorted to, the eye is destroyed by sloughy ulceration. There is always a discharge of unhealthy mucus from nose, but this is in comparatively large quantity when the tumour is situated in the nostril, which it sometime is. The inflammation is liable to extend to the brain; when this happens the animal is cut off, and this spreading of the inflammation to a vital organ is the usual cause of death. If the inflammation confines itself to the orbit the extent of the mischief is the loss of its contained organ, the eye, and with respect to other sites, the inflammation being confined thereto, a foul ulcer results which heals slowly.

This affection is not uncommon. It appears to be an inflammation of the cellular membrane situate in the usual site of the disease, which if uncontrouled speedily runs on to sloughy suppuration. The disease is supposed to be occasioned by sudden check of perspiration as it usually occurs after the animal has drank plentifully of cold water immediately after coming off a march. If active curative measures are not early resorted to the animal usually dies; and the ultimate termination of the malady in cure or death is estimated by the early or protracted appearance of the tumour. In the former case, recovery may be anticipated-in the latter, death. 


\section{$(6)$}

The native treatment consists in firing on head, giving stimulating Mussals, and blowing acrid substances into the nostrils with the view to occasion increased secretion of mucus. Receipts of what are considered most approved Mussals, and those for the preparation of irritating powders to be blown into nostrils, are given in Part $3 d$ page 25.

The native treatment ought not to be followed as, at best, it is inert.

Treatment.-Bleeding and purgation must be resorted to, and practised freely. Instruction for performing the operation of bleeding will be found in Part 4 th page 54, bleed to one gallon or one and a half gallon if the animal be in high condition. Give a full dose of Aloes, namely, four ounces with Milk, as described Part 3d page 27, or half an ounce of Calomel. The affected part ought to be well fomented, a practice which alone will go far to ameliorate the severity of the affection-more especially if early resorted to, it goes far to subdue the inflammation and therehy proportionally to diminish the extent of suppuration and sloughing-See Fomentation, Part 3d page 27.

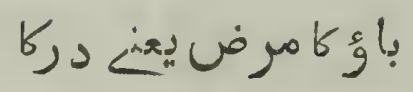

\section{BHAO-KA MURZ; OR DHUDKA.}

Histony. - This disease as shown both by symptoms during life, and dissection after death, has, as holds with respect to Elephants, two seats, that of the brain and that of the lungs. At present the disease as existing in the former seat will be considered. Bhao-ka Murz, when affecting the brain, consists either in inflammation of that organ, or in an apoplectic effusion of blood or serum within the skull, and occasioning death by pressure on the contained vital organ. The apoplectic variety usually supervenes suddenly and without any premonitory indication and is speedily fatal. The animal proceeds on its journey and down to the moment of seizure may evince no ailment; it then suddenly staggers, falls down and dies. The apoplectic variety usually has this sudden termination, and in most animals (all that have died of this disease at this Depôt have been minutely dissected under my own eye) effusion either serous or sanguineous within the skull has been discovered.

The inflammatory variety of the disease is indicated by the animal attempting to bite its keeper or whatever is within its reach, usually it is unable to stand-there is a somewhat convulsive motion of limbs, and occasionally it rolls on its back, bellowing loudly the while; the ears are stiff and cold, and the surface of the body is generally in the latter condition. This disease is equally prevalent in all seasons of the year, and arises generally from sudden check of perspiration, as the washing of the animal soon after coming off march, and before it is sufficiently cooled-but in all probability the continued exposure of the animal to an 
ardent sun, is a predisposing cause, acting on the head so as to impair the healthy condition of its vital contents, and thereby causing the animal to be the more sensible to morbific causes.

The native treatment consists in giving stimulating Mussals, and in introducing between eye-ball and eye-lid acrid substances with the view to cause copious lachrymation. Firing around navel and along sides of body is also practised. It is almost unnecessary to remark that this practice as a whole is at least useless, if not positively injurious.

Treatment.-1st. The Apoplectic variety-Cold applications ought to be applied to head, while the trunk and hinder extremities are kept hot with fomentation sedulously applied. Blood to the extent of 20 pounds ought to be drawn off. An aperient given. The unjunum, or lachrymal preparation (Vide Part 3d page 25) may be introduced within the eye-lids, with benefit, after the measures just named have been practised. $\cdot 2 \mathrm{~d}$. Inflammatory variety. - This variety being on its nature an inflammation of the brain or its containing membranes, requires the most active measures that can he resorted to in order to allay inflammation. Bleed to the extent of 20 pounds-apply cold lotion to head and warm fomentations to body. Give an aperient. The bleeding may be repeated to the extent of 10 or 15 pounds if need be. The fomentations to body and cold lotion to head ought to be continued uninterruptedly till a very decided and prominent improvement has occurred.

\section{MOORGHEE-KA MURZ;}

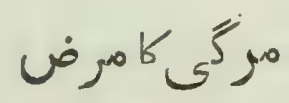

\section{OR EPILEPSY.}

History.-This complaint which is not uncommon, is a regular epileptic affection and has received its native name from the circumstance of the animal showing symptoms which resemble those shown by the domestic fowl when labouring under a similar ailment.

The approach of this malady is marked by no symptom. The animal continues healthy to all outward appcarance up to the supervening of the disease; it eats as usual, does not fall off in condition, and continues to work. The near approach of a fit is marked by the animal walking around its picquet restlessly, and making an occasional gutteral roar. It then falls down, the neck is drawn backward so as to be bent on itself nearly - the limbs are moved convulsively - the animal rolls from side to side, and continues with little interruption the gutteral roar. 
The fit usually continues from four to eight minutes, at the expiration of which time the animal gets up, and commences eating as if nothing had happened. The return of fits is very variable as to time: several may occur in 24 hours, and with nearly equal intervals between. In other cases, several days may elapse between those on which the fits occur; and on the days of seizure they may be more or less numerous, sometimes they occur daily and in variable number.

I have dissected several animals which have died of this ailment, and in all there was found a morbid sanguineous fluid in the spinal canal. All the thoracic and abdominal organs were usually found healthy, and when not, the kind and degree of the derangement was not such as to occasion the disease: 1st, because, such appearances were not always found in those which died of this affection; and 2ndly, in several of such in which they were seen the disease under consideration bad not uniformly pre-existed-indeed, similar appearances have been traced in animals which died from old age. The disease is doubtless one of the nervous system. It is very variable in its continuance, and according to my own experience and to that of intelligent and old Camel attendants it is uniformly fatal. The native treatment consists in giving stimulating Mussals, and in blowing up the nose powder's to increase secretion of mucus. This treatment is of no use. Part 3d page 28.

TrEatMent.-Bleeding has been found to protract the recurrence of the fits; and in a given time materially to diminish their number. All the cases, however, that have come under my treatment have ultimately proved fatal; but this I attribute more to the advanced progress the disease had, from undisturbed continuance, been allowed to make, than from the nalure and character of the disease itself. The animal ought to be scoured out with Aloes (vide Part 3d page 27.) The head fired, or a blister applied to neck - and alterative doses of Calomel and of Sulphuret of Antimony given.

The origin of this disease, in all probability, consists in undue exposure. I understand that private breeders of the animal are particularly attentive to secure shelter as well from the inclemency of the weather, as from the direct influence of the sun: and Hyder Alli, I am told, had sheds for his Camels, so that it appears to be the opinion of the native that the sun can exert a prejudicial influence on the animal. In this opinion I fully concur, and have little doubt but that the sun is a primary cause of the disease under consideration.

\section{CUMMAUN-KA MURZ.}

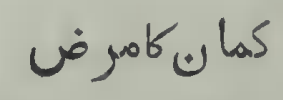

History.-This also appears to be a disorder of nervous system. Suddenly the neck becomes drawn to one side, apparently from the corresponding muscles of the other side of neck becoming paralytic. The animal is unable to walk steadily, 


\section{$\left(\begin{array}{ll}9 & 1\end{array}\right.$}

but totters on its limbs, or is altogether unable to stand. About half of the animals seized with this affection die from its effect. It is most prevalent during the rainy season.

The native treatment consists in firing neck from ear to shoulder in a line on both sides, and in giving stimulating Mussals. Pages 38-39.

Treatment. - The stimulating Mussals ought to be discarded-blistering or a seton would be more efficacious treatment than the firing. Alterative doses of Sulphuret of Antimony and Calomel ought to be given.

\section{JOLAH-HINDOOSTANEE. جه \\ LUCKWAH-PERSIAN. لقوا}

\section{PARALYSIS OF THE HINDER EXTREMITIES.}

Histony.-In this disease the animal is suddenly seized with loss of power of hind legs: if standing, on the supervening of the affection, the animal falls down: if lying down, it is unable to get up. It is most prevalent in rainy weather. The animal continues to feed well; nevertheless the disease is incurable according to native experience, and altogether unfits the animal for further service.

Native Treatment-Firing over haunches and across back; and giving stimulating medicines containing, amongst other ingredients, Tereeak Farook. Part 3 d page 39.

Treatment.-Blistering over that part of the spine situate in the loins, and keeping blister open is a more judicious treatment-conjoined with alterative doses of Sulphuret of Antimony and Calomel.

\section{DISEASES OF THE CONTENTS OF THE CHEST. POEPRA OR POEPSA.}

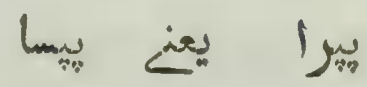

History. - This is an inflammation of one or more of the contents of the thorax. Most usually it is an inflammation of the lining membrane of the trachea; though the substance of the lung be affected, or even the membrane lining the internal sides of the chest called the pleura. It also consists in an effusion into the substance of the lungs of serous fluid-a variety which is very rapidly 


\section{$(10)$}

fatal, and to which the Natives give the name Bhao. When the membrane lining the wind-pipe and its ramifications constitute the principal seat of the disease, there is much cough; the breathing is more or less hurried and laborious, and the animal evinces considerable distress. There is occasionally running from eyes; the ears are cold, and so is surface of body. When the substance of the lung is the principal seat of the ailment, or when this is effected contemporaneously with the membrane of the wind-pipe the breathing is very laborious, as evinced by the heaving of flanks and the greater distress of the animal. In this variety, the Natives consider that the lungs are over-distended with air and that the difficulty of breathing arises from the lung being forced by over-distension into lower part of neck, thereby preventing the free passage of air into and out of the organ. When the lining membrane of the chest and that of the lung is the seat of disease, it is difficult during life to pronounce decidedly and correctly that such is the seat of the animal's ailment. There is not much cough; but from the hurried breathing together with the circumstance being observed of. The bowels are in a healthy condition; it may be inferred with considerable confidence in the correctness of the inference that the animal is labouring under the variety of thoracic disease, now under consideration. After death a collection of fluid is generally found in the chest.

This class of affections as might be expected is more prevalent in cold and rainy weather than during the hot season. The native treatment consists in giving Mussals of a stimulating character. Firing is never practised. This treatment has not even the negative character of doing no harm-it is possitively injuriousfeeding the disease instead of subduing it.

Treatment.-This disease being severe inflammation of a vital organ the most active measures for subduing inflammation ought to be practised and with the least possible delay. Bleed to two gallons (vide Part 4th page 54, for instruction for bleeding.) Give four ounces of Alues dissolved in a seer of Cow's milk combined with a drachm of Tartar Emetic. Foment the whole of the trunk (vide Part 3d page 27, for instructions for fomentation.) This latter operation is highly efficient when preceded by bleeding. The subsequent treatment consists in giving half a drachm doses of Tartar Emetic every 4 th hour; persevering with the fomentationsand if the Aloetic aperient do not operate four hours after exhibition, give half an ounce of Calomel made into a ball, with a drachm of common Soap. The animal ought to be well defended from the elements in a shed.

\section{KOOD-KA MURZ.}

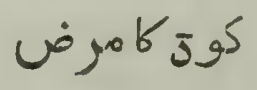

Histony.-In this affection, there is cough, difficulty of breathing, and a discharge of thick mucus from nose. It appears to be a severe Catarrh and makes its appearance during the monsoon and cold weather-disappears in hot weather. 


\section{$11)$}

Animals seized with it frequently become under Native treatment, permanently incurable. On each occasion of a paroxysm supervening, which occurs regularly every monsoon, relief is obtained by the remedial means recommended below. The cough is sometimes particularly severe.

Native Treatment.-Stimulating Mussals-No firing. This practice is inert, if not injurious.

Treatment.-This too is an inflammatory affection and though of much less severity than the ailment just considered; nevertheless requires the same kind of treatment though less potent in degree. Bleed the animal to $\frac{1}{2}$ or a whole gallon, apply fornentations to neck-keep the trunk of body warm. Give a drachm of Aloes with a drachm of Tartar Emetic. The subsequent treatment consists in repeating the Tartar Emetic twice daily-repeating the Aloetic purge if need be and persevering with the fomentations.

The animal ought to be sheltered. When the complaint has assumed a Chronic form, blisters to neck or a seton will prove very beneficial: and the extent of bleeding should be less in the Chronic form than in that of the recent affection- $-\frac{1}{2}$ a gallon being the extreme extent to which to carry it.

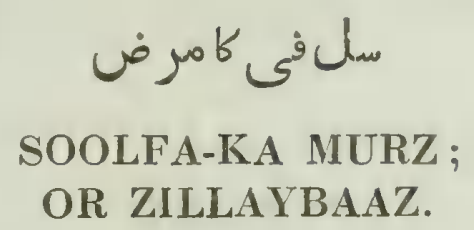

History.-This disease, which is also an affection of a Catarrhal kind, is characterized by difficulty of breathing; and upper surface of tongue becoming very white, and presenting from enlargement of the papilloe a rough appearance. There is grinding of teeth. It appears in cold or rainy weather.

Native Treatmext. - Stimulating Mussals and Errhiues. Page 34.

Treatment. - The same treatment may be observed in this variety of Catarrh, as in that of the foregoing affection.

\section{CHOODEE-KA MURZ.}

$$
\text { هو5 عي مبرض }
$$

History.-This also is a Catarrhal affection, and is characterized by diffculty of swallowing, arising from tenderness of larynx and pharyns, and some 
swelling of upper part of neck. There is running from eyes of lachrymal fluid. It usually occurs in rainy and cold weather, but may arise during the hot season if the animal be too suddenly cooled when heated. It is a mild variety of Catarrh not attended with cough.

Treatment. - The curative measures recommended for Soolfa-ka-Murz, are to be adopted.

KUDDAH-KA MURZ.

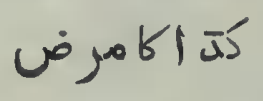

Histony.-A swelling of the larynx, said to arise from animal over-stretching neck when reaching to a high branch to obtain food.

Treatment.-Fomentations in mild cases. If there be tenderness in upper part of neck, the seat of the swelling, $\frac{1}{2}$ a gallon of blood ought to be abstracted. Part 4th page 54.

\section{AFFECTIONS OF THE STOMACH.}

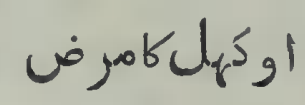

OOKAHL-KA MURZ, OR JOUGGAUL.

\section{A VOMITING OF CONTENTS OF STOMACH.}

History.-The irritability of stomach is the prominent symptom of this ailment. It arises from inflammation more or less extensive and severe, of that organ. The disease may arise from over-distention of stomach from too much food. There is a herb called in Duckanee Goomchee-ka-puttha, of which, if the animal eats, the disease is likely to be supervened: but this herb does not occasion death. The disease is most prevalent in hot weather when the elements are concerned in its production.

Treatment.-Here most active measures are required and to be practised without delay in the cases arising from inflammation, from over-distention, \&c. Bleeding ought to be practised to two gallons; drawing off the blood from apertures in either jugular vein. Fomentations to trunk ought to be persevered in. The animal ought to be prevented eating or drinking till the irritability of stomach be overcome, as either food or drink given previously only tend to keep up that condi- 
tion of the organ. And attention ought to be paid to the kind of food given subsequently. A gram diet for a few days will be sufficient-afterwards grass may be added and then a gradual return to ordinary food.

\section{ملول ينغ سول \\ SOALE, OR MALOLE. COLIC.}

History.-Of the above terms, Malole is given to a milder and Soale to a severer and more protracted spasmodic disease of the intestines. Its occurrence is marked by great restlessness of the animal, which lies down to press its stomach on the ground, or on its legs when in the couchant position, rises up, moves from side to side; symptoms all the result of bodily distress arising from Colic. The animal leaves off feeding; and is subject to this ailment most frequently in the cold weather. The bowels may be open or otherwise. The urine is scanty or wholly suppressed, and is always high coloured. The surface of body is hot, and also ears.

The Native treatment consists in firing on sides and across belly and in giving stimulating Mussals, but containing no opiate.

TreatmenT.-Bleeding ought to be practised without delay to one gallon or one and a half. The trunk of body is to be well fomented and the operation steadily persevered in till cessation of symptoms, indicating distress of the animal, be supervened. An Aloetic purge with 1 drachm of Opium is to be given; after the spasmodic action has subsided, and if the attack continues for a couple of hours after bleeding unrelieved, a copious injection of warm water, say two gallons, containing an ounce of Laudanum, will prove very useful. The after treatment consists in persevering with the fomentations, repeating the injection with only $\frac{1}{2}$ ounce of Laudanum, and if decided relief be not secured, three hours after bleeding, this operation ought to be repeated to the extent of half a gallon.

\section{ز}

\section{ZAARBAHD.}

\section{DROPSICAL AFFECTION.}

History.--This a dropsical swelling of the greater part of body, commencing about the back and lower part of belly, thence extending forward to raafa or protuberance on breast bone, on which the animal rests when in the couchant position- 
thence the swelling extends up neck eventually reaching head. The back is exempt from swelling. Bowels healthy, also urine. The surface of body of healthy temperature. It is most prevalent during the cold and rainy seasons; and is a fatal disease. This much resembles the Zaarbahd of the Elephant, and appears to be somehow connected with an affection of the spinal marrow. If the animal be brought under treatment early, the withdrawing of two quarts of blood will prove beneficial-firing alongst either side of spine and giving $\frac{1}{2}$ a drachm doses of Calomel. When the disease is of some weeks standing it appears to have progressed too far to be within the reach of successful treatment. The means to be practised in this as in the earlier cases are the same though cure of the former is much less likely to be affected than of the latter.

\section{ZOOLAAB, OR PURGING.}

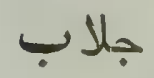

Histony.-This may arise spontaneously during rainy or cold weather, or may be the result at commencement of rainy season, of the animal eating of the young and tender growth of the plant called Kaateemut, of which the animal is very fond, and which at a greater age is a very nutritious diet. If allowed to continue, this affection may cause death from the weakness thereby superinduce.

The Native treatment consists in giving Narcotics, amongst which is Ganjah or Extract of Hemp.

Treatment.-The Native Mussal No. 1, (vide Part 3rd page 28, may be given conjoined with $\frac{1}{2}$ a drachm of Opium. Fomentations will prove very useful.

\section{INDIGESTION.}

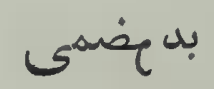

Histony - Before leaving the section of abdominal affections, I must allude to a state of the digestive organs called as above for the want of a more appropriate popular name Indigestion, in which though no prominent individual symptom is to be observed, with the exception of falling off in condition of the animal; there is to a greater or less degree weakness of one or more of those organs. The protracted continuance of this unhealthy condition occasion a cutaneous eruption over trunk, and indeed occasionally throughout whole of the surface of the animal and a most obstinate eruption it is to get rid of.

In animals which have died from other causes while labouring under the affection now under consideration, I have occasionally found cysts varying in size from half 


\section{$(15)$}

an inch to two inches in diameter, and more or less numerous, though six is the maximum number I have observed. They are very elastic so that when cut into the transparent fluid they contain, is projected to the distance of some two or three feet. They are usually found in the liver, though I have observed them also in the substance of the lungs. But these cysts are not an uniform concomitant of this affection.

Treatment. - The treatment found most efficacious is an alterative one-

Half a drachm of Calomel,

A drachm of Sulphuret of Antimony,

made up into a ball with Soap, ought to be given for three consecutive nightsafterwards a purge of Aloes, and the ball continued on alterative nights with an occasional purge. When the cutaneous eruption exist the surface ought to be washed with Soap and water, and particular attention paid to the grooming of the animal.

\section{AFFECTIONS OF URINARY ORGANS.}

Of the following three affections I have not seen any cases-the description and treatment are those of the Serwans.

\section{SOOZAAK ;

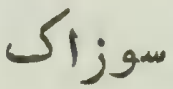 \\ OR BLOODY URINE.}

History.-In this affection, which shows itself in hot weather only, the urine is scanty and consists of about equal parts of urine and blood. It is passed freely. The disease is not u fatal one.

Treatment,-This consists in exhibiting Mussal No. 1. Part 3d page 28.

\section{PHUDMOOTE.}

\section{تون \\ DIFFICULTY OF PASSING URINE.}

Histony. - In this affection the urine is passed only by drops. It is a disease, which, although not a fatal one, continues usually for several months, during which the animal falls off in flesh. 


\begin{abstract}
$(16)$
Treatment.-This consists in exhibiting Mussal, No. 1. Part 3d page 28.
\end{abstract}

\title{
DHUNDEE-KA MURZ.
}

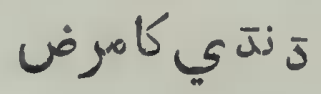

History.-This is a species of madness invariably associated with the protrusion of the penis. It does not arise from any desire for procreation, and is a fatal disease : and fortunately is not one of frequent occurrence, and when it does occur it does so only during hot weather.

Treatment.-The Native treatment consists in giving cooling Mussals us Nos. 3 and 4, Part 3d, pages 45-46. An Aloes purge ought to be given after a full bleeding has been practised.

\section{UDDHARUNG-KA MURZ.}

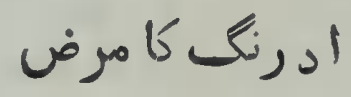

\section{RHEUMATISM.}

Hisrony. - This affection is situated in the muscles both of body and legs to a greater or less extent. The limbs become to $u$ considerable degree stiff, so that the animal walks lamely and with pain. The affection usually supervenes when the animal is standing: so that when labouring under it, it is unable to lie down. Animals are most subject to it in rainy and cold weather-is seldom seen during the hot season.

Treatment.-The affection does not continue above three days if the Stimulating Mussal usually administered by the natives be given. Fomentations will also prove useful. See page 46 for native treatment.

\section{JENNUK VAYE;}

$$
\text { جنك }
$$

\section{OR PARALYSIS.}

History.-It is confined to the hinder extremities, both of which are contemporaneously affected. The animal moves its binder limbs in a dragging manner 


\section{$17 \quad)$}

when walking. It supervenes equally during all seasons, and is to be distinguished from Rheumatism, by the animal evincing little pain, but moving hinder legs in a dragging manner. It is removed in about a month by firing, and should this not be practised the recovery will be more distant but is usually certain of occurring.

Treatment.-The native treatment consists in firing from the ear along neck ; alongst trunk, near spine. A purge ought to be conjoined to the above treatment; and should the system appear oppressed-more especially, if the affection supervene after continued exposure to an ardent sun on a long march, the animal ought to be bled to half a gallon.

\section{TUMOURS.}

History.-Of tumours, the Camel is subject to a very great variety, some situate in glands-others below skin in various parts of the body. Of the former variety is

\section{EAKUD, OR GOROOSH-KA MURZ.}

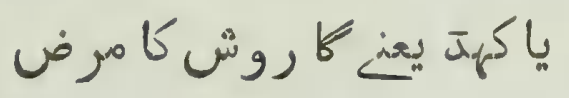

This is a swelling of two glands situate near root of neck on lower part. The glands in health protrude somewhat beyond general contour of body, and are distinctly visible. It is equally liable to occur at all seasons, and animals in good condition are subject to it equally with those that are not. It occurs in each animal only once but not before the 10 th year of age. This swelling invariably goes on to suppuration according to native experience. The cyst sloughs out leaving a foul deep ulcer. The animal usually can work when this is present, though, if opportunity exist, of course relief from duty during treatment.

Treatment. - The native treatment consists in applying a stimulating liniment, with the view to expedite suppuration. $\mathbf{\Lambda}$ poultice ought to precede the native application, afterwards it, or camphorated oil, or a solution of blue stone, or on the principle of cauterization, boiling oil may be introduced into the sloughy hollow ulcer to clean the surface of those sloughs. The after treatment consists in the continued application of camphorated oil ; or blue stone, and excluding as much as possible the external air-Part $3 \mathrm{~d}$ page 26.

\section{RUNDUK.

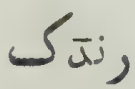

History.-This is a swelling always terminating in suppuration of the glands situate in the groin. Animals of all ages are equally liable to it. It occurs during hot weather only. The animal is unfit for service when the disease exists. 
Treatment.-Native treatment consists in applying stimulating embrocations or liniments with the view to expedite suppuration. The same treatment is to be observed for this affection as for Eakud. Part 3d page 48.

\section{RUSSOOLEE.}

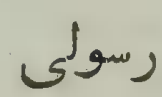

History.-This is a tumour about two inches diameter situate below skin, and consists of a cyst containing caseous or cheese-like matter. It has no particular site, as it may occur in any part of surface. It invariably goes on to ulceration, when the matter of the cyst escapes, and this latter sloughs out. It occurs during all seasons, and animals of all ages and variety of condition are attacked equally by it. It is not of frequent occurrence, and does not throw the animal out of work.

Treatment-No native treatment is practised. A purgative preceded by an Alterative ball of Calomel and Sulphuret of Antimony ought to be given. Part 3d page 25.

\section{BALE.}

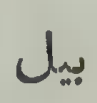

History. - This is very troublesome and acrid tumour of a suppurative kind which may appear in any part of the body, and in several numbers at a time; they usually attain to a size of two inches in diameter. When situate on the body they are called Nurbale; when on the legs Maadee-bale; but there is no difference beyond site. The tumour whether on body or limbs being of the same nature. After one set of tumours have appeared suppurated and nearly healed, another set appear, and go through the same stage, to be succeeded by successive sets which eventually render the animal unfit for further service. It is an obstinate disease, and fortunately is one of rare occurrence.

Treatment.-Alterative doses of Calomel and Sulphuret of Antimony ought to be given with occasional purges. Part $3 \mathrm{~d}$ page 25.

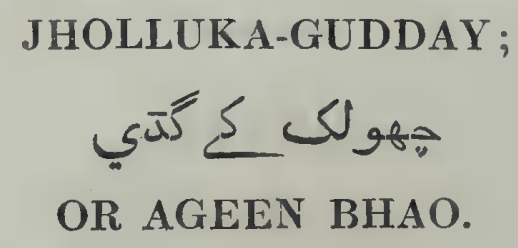

HisTory. - This is a suppurative eruption which breaks out over different parts of body, and usually is the result of over-exposure to an ardent sun. The eruption commences in vesicle and terminates by suppuration. 
Treatment.-An occasional purgative. The eruption should be washed with warm water daily, and afterwards Camphorated Oil applied.

\section{SURDHEE.}

\section{سردو \\ COLD.}

HISTORY. - This appears a febrile affection, arising from the animal being subjected to cold atmosphere, or water producing a sudden check to perspiration. The presence of the affection is shown by the animal leaving off eating and ruminating.

Treatment. - The native treatment consists in giving stimulating Mussals, which appear efficacious. Fomentations and shelter expedite a cure.

\section{KAAREESH.}

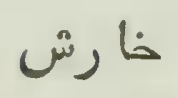

1TCH.

Histony.-The Camel is very subject to cutaneous eruptions, arising either from insufficient grooming, from continued exposure to an ardent sun, or from impairment of the digestive functions. That known by the name Itch is to be distinguished from the other varieties by the discharge being of a suppurative kind, that of the other being of a serous or glutinous kind, which is proportionally more abundant than the quantity of discharge arising from the Itch.

Treatment.-The application of the Native Mussal, which consists of Sulphur, marking nut and milk-hedge juice, is very efficacious. The recipe is given. Part 3d page 51.

\section{RAHAFAY.}

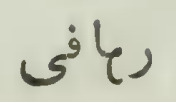

History.- The Rahafay is that large tuberosity on the breast bone of the Camel on which it rests when in the couchant position. This tuberosity is in structure partly membranous, but principally cartilagenous. 
It is a frequent seat of disease being subject to inflammation when injured, whilst the animal with load on back is placing itself in the couchant position with the view to being unloaded; and the inflammation is of a kind which is liable to go on to a sloughy suppuration. Sometimes incurable, always tedious. When the suppuration occurs deep in the substance of the taberosity, the discharge instead of working outward to the surface generally burrows inwards into the cavity of the chest. When this happens that part of the breast bone covered by the Rahafay becomes absorbed to a greater or less degree-that part of the lung in the vicinity of the affection inflames and suppurates, and the pus goes on accumulating in the cavity of the thorax, till the contained organs, either from pressure or destructive suppuration, are unable to perform their function aad death results.

The native treatment consists in firing around the base of the tuberosity-a treatment which in the inflammatory stage of this affection can do no good; and most probably will do much mischief.

Treatment.-In the inflammatory stage the animal ought to be bled to a gallon, and the Rahafay well fomented. Fomentations in this complaint are very useful. These two means-the latter persevered in, may arrest the inflammation and cure result. But there is a great tendency to suppuration, and when pus is formed it ought to be let out by incision, early; otherwise it burrows through the substance of the tuberosity, thus giving rise to sinuses more or less extensive which are very tedious of cure.

When cases in this predicament are brought for treatment the sinuses ought to be laid open and dressed with Solution of Blue Stone or Camphorated Oil. Part $3 d$ page 26.

\section{ULCERATED FEET.}

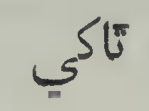

History.-The feet of the Camel are frequently injured by going over stony roads, or on ground cleared of brush-wood, on which but stumps remain standing. In the latter case a fistulous wound, more or less deep, is inflicted, which is very tedious of cure. Indeed the same remark applies to all ulcers whether superficial or fistulous of the feet.

Treatment.-Superficial ulcers require poulticing in the first instance to clean them; they are then to be dressed with Camphorated Oil or Blue Stone, bandaged, and the whole inclosed in a leathern boot to exclude dirt. Fistulous ulcers are to be laid open if extending parallel with surface. If very foul, the most powerful and speedy detergent means is, the application of a red hot iron to the sloughy surface-fistulous ulcers at right angles to surface require, if foul, to be 
cleaned with the red hot iron, afterwards dressed with Camphorated Oil or Blue Stone solution. A piece of cloth being introduced to fill up the entire space of the fistnlous ulcer that the healing process may go on regularly and progressively from the bottom of ulcer to the surface.

\section{SORE BACK.}

$$
\text { טיה }
$$

History. - Of all affections appertaining to the Camel sore back is the most frequent unless the Serwans are under some direct and present superintendence, or are held responsible for its non-occurrence under other than unavoidable circumstances. Sore back is occasioned by the unequal pressure of the saddle, and this unequality of pressure may arise either from the carelessness of the Serwan as to adjustment or from the saddle getting out of order. Comparatively few animals sent on Command from this Depôt returned without being injured more or less in this respect, until Lieutenant Colonel Watkins, Deputy Commissary General, (then in charge of this Depôt) instituted the rule that for all such injuries as could not be shown on the part of the Serwans to arise from unavoidable circumstances, the Serwans were to be retrenched half pay so long as their respective animals were under treatment; prior to the instituting of this rule, Camels with sore backs, found by far the greater majority of cases; subsequently it is unusual to have a case of the kind under treatment.

Treatment.-The usual treatment of ulcers is to be practised-poultice to clean-afterwards apply Camphorated oil or blue stone solution. A mixture of wax and oil in the proportion of two ounces of the former, to one of the latter is then to be applied, and over this a piece of cloth. The more effectually the air is excluded the more rapidly will cure be effected.

\section{FRACTURES.}

History - Fractures of bones of extremities, as also dislocations, I have found incurable. The mechanical power of a capstan and spokes I have found insufficient, unless so great a degree of force had been used as would tear off the limb, or otherwise injure to an extent that would render the limb useless, as also its muscular and other fleshy parts.

The only fracture that has been cured of the cases that have come under treatment is that of the lower jaw. The accident occurred from a fall; and the seat of the fracture was about the middle of the bone; and on both sides an iron splint of 


\section{$(22)$}

the following shape and dimensions was used. The animal was fed on gram while under treatment, by hand after six weeks, a perfect cure was effected.

Shape and dimensions of Iron Splint.

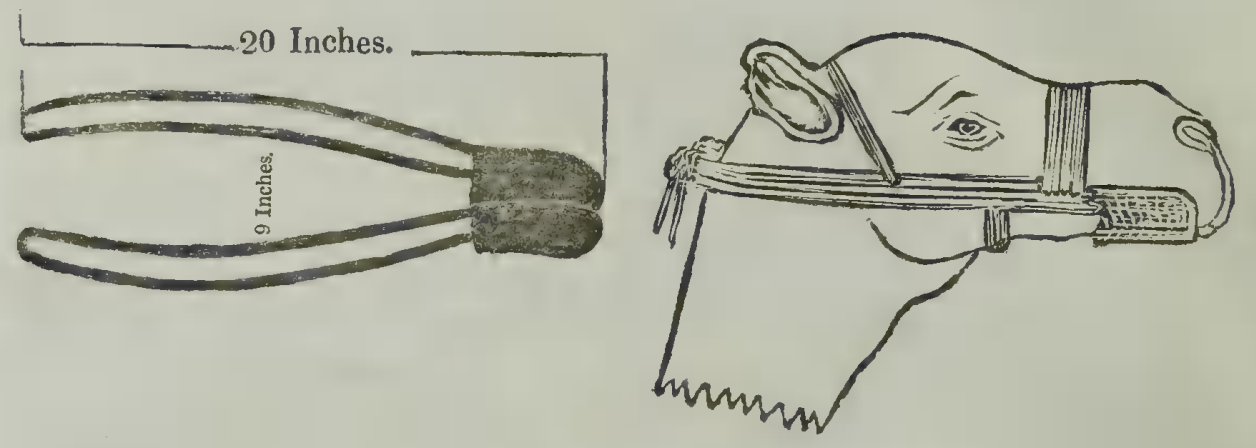

DOOBLA-LAAGAR-KUMZORE.

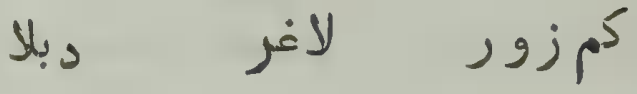

WEAKNESS.

History.-This arises either from old age, or from over-work. The animal falls off in condition and is weak. Nevertheless it continues to have a good appetite.

Treatment.-Rest, occasional alterative doses of Calomel and Sulphuret of Antimony, with the use of the Native Tonic Mussal, No. 2, Part 3d, page 50. 


\section{PART SECOND.}

A vigilant superintendence over the Serwans will go far to preserve the efficiency of the animals under their immediate charge; whereas if this class of people are left to themselves, they are liable from indolence, carelessness, or from a wish not to proceed with a force to render their animals unserviceable, either temporarily or permanently. Instances of this malpractice have come under my own notice. The advantage of punishing by stopping a portion of pay while the animals injured from carelessness are under treatment; as was done here by Lieutenant Colonel Watkins have already been noticed, page 21, and, I am informed by an Officer of H. M. 2d Regiment, who served throughout the Affghanistan Campaign under Lord Kean, that he was enabled by carefully superintending his Serwan, to take his Camel through the Campaign, at the end of which it was equally healthy and efficient as at the commencement. Officers less attentive to their Cattle were much inconvenienced by inefficiency or loss. The Officer just alluded to was particular in having his Camel well groomed; and in avoiding exposure, as far as was practicable to sudden and to great alterations of temperature, and after a hard day's work, giving it half a bottle of Arrack or other stimulus.

The best places for picqueting Camels are topes if not situate on wet ground. They thereby are sheltered to a greater or less degree from the sun during day; and during cold weather from the great difference of temperature which in that season exists between that of night and of day. Much care should be taken when coming off a march to prevent sudden check of perspiration, for which purpose the jewel or coarse covering ought to be put on the animal immediately after its load is removed, and this ought to be worn during night, particularly during the rainy season and cold weather. On coming off a long march, or when the animal is worked hard, a stimulating Mussal, for which receipts are given, page 52, will be useful: and while on the march, rough roads should be avoided as far as practicable, for the feet of the animal are very subject to injury as already noticed, page 20: and when injured, the cure, if practicable, is usually tedious. On the other hand slippery roads ought to be avoided as much as possible, for the animal on such roads is far from being sure-footed. The Serwans are in the habit of passing a rope between the hinder legs of the animal when going alongst slippery roads, so as to allow only of short steps being taken; and in the event of one foot slipping it may thereby be brought up. Dislocation of the thigh joint is not an uncommon result of the animal slipping; also fracture of some of the bones of the extremities.

Another important point to be attended to in preserving the efficiency of the animal, is attention to the condition of the saddles. If these are allowed to get out 


\section{$(24)$}

of order, sore back will be the result. The Serwan ought to be ordered to report at once when the saddles become so, and unless good and conclusive reasons can be assigned for injury from this cause it ought to be regarded as one arising from carelessness. Under the head "lujury of back" in the 1st part of this Memoir, will be found some remarks, showing the great advantage of vigilant superintendence in this particular.

\section{EXPOSURE TO SUN.}

The Camel, like the Elephant, doubtless suffers from continued exposure to an ardent Sun; which therefore, as far as is practicable, should be avoided. The Epileptic affection described at page 7 of this Memoir, $I$ have reason to think arises from exposure; and I have been informed that Tippoo defended his Camels from the Sun by sheds. The Breeders of the Camel are attentive to this point, securing their shelter by topes. It therefore becomes a question how far it is advisable to preserve the head of the animal when employed during hot weather by a wadded piece of cloth.

\section{DIET.}

Gram is the best, next to this Bengal-gram, next, the pods of gram. The combined use of the leaves of the Peepul, and of the Banyan tree, is apt, particularly during hot weather, to occasion the disease called Malole, vide page 13. 


\section{PAR'T T H I R D.}

THE Materia Medica, or a summary statement of the virtues and doses of the Medicines found useful in the treatment of the Camel : and a statement of several curative measures.

\section{ALTERATIVES.}

This class of Medicines is used extensively and generally efficaciously by the Serwans in diseases of an obscure and chronic kind, mainly connected with diseases of the digestive organs.

Calomel.-This, though not prescribed by the Serwans, is a useful alterative medicine, given in doses from $\frac{1}{2}$ a drachm to one drachm, conjoined with the following.

Sulphuret of Antimony is given in similar doses.

Tartar Emetic in half a drachm or drachm doses is useful in clearing the surface and improving the coat.

\section{ANTHELMINTICS.}

The alimentary canal of the Camel, so far as I have had opportunity of observing from dissections which have been numerous, is not infested with worms of any kind, so that this is a class of medicines, in the use of which should they ever be required in the Camel, I have no experience. With respect to worms the alimentary canal respectively of the Elephant and Camel differ widely-the former, as stated in the Memoir of the Elephant, being very subject to be infested with two species of worms.

\section{CARMINATIVES AND STIMULANTS.}

These are useful classes of medicines. The former combined in Tonic Mussals; and both in Spasmodic affections of the bowels. They are Sweet Flag, Ginger, Cloves, Chillies, Arrack, exhibited in doses mentioned further on as stated 
under the head of Native Mussals. Half a bottle of Arrack given to a Camel when coming off a long day's journey occasionally exhibited while on the line of march, will go far to preserve the efficiency of the animal.

\section{EMETIC.}

I knew of no substance that has an Emetic effect on the Camel. With a view to learn the effects of Tartar Emetic, it was exhibited on eleven consecutive days, but with no visible result whatever.

On the Ist day a drachm, or 60 grains were given every 3rd hour; four drachms or half an ounce had been given.

2nd day. Two drachms every 3 rd hour till an ounce had been given.

3rd day. Three drachms, at similar intervals, (3 hours) till an ounce and a half had been given.

4th day. Four drachms, at three hours interval, till two ounces had been given.

5th day. Six drachms every 3rd hour till three ounces had been given. During the five subsequent days three ounces were given daily, at 7 A. M., noon, 4 P. M., and on the 11 th day two ounces were given, one at 7 P. M., one at noon. Making a total of twenty-five ounces taken in eleven consecutive days, but without the slightest visible effect. The animal throughout continuing to eat its fodder aud daily allowances of Gram.

Though this medicine be not useful as an Emetic, it is as an Alterative in $\frac{1}{2}$ a drachm to 1 drachm doses.

\section{EXTERNAL APPLICATIONS.}

Camphor dissolved in Castor or Jinjili Oil, in various proportions, from two to six ounces of the former to eight of the latter, is a useful detergent application. Turpentine and Pitch may be added in the more foul ulcers. detergent.

Blue Stone, either in the pulverized state or in solution, also proved a useful

A red hot iron to the surface of very foul sores expedite the cleaning of them; after which the weaker solution of Camphor in Oil expedites the cure. 
Red precipitate ointment is also an useful external application to clean ulcers, expediting the healing process.

Boiling water or oil may be advantageously used with which to wash the surface of foul ulcers, by which means the sloughy surface is speedily thrown off and succeeded by a healthy granulating one.

\section{FOMENTATIONS.}

This is a very useful external application, as well for acute internal diseases, as for sprains and rheumatic affections, and for discussing some kind of tumours. For internal diseases, the trunk of the body ought to be fomented with hot water: II couple of cumblies of coarse blankets being previously put round the body, which is kept hot by the application of hot water to successive portions applied hy means of a piece of cloth fixed to the end of a piece of bamboo some five or six feet long; which is alternately dipped in pot of hot water and applied to cloth.

For the limbs or other parts a similar plan may be observed.

A very convenient mode of applying heat in the shape of fomentation is one commonly resorted to by the Cattle attendants, is, that of mixing cow-dung with hot water till the mixture have the consistency of a thin paste; this is heated in a common chatty, and applied direct to the surface to be fomented, with the cloth and bamboo brush-like apparatus above described.

\section{OPIATES AND ANTI-SPASMODICS.}

Of this class-Opium and Assafætida are the most efficient and are given in combination with Carminative in flatulent and colicy diseases of which Native recipes are given further on.

\section{PURGATIVES.}

I have found only two substances to be efficacious as purgatives, namely, Aloes and Calomel. The former is given in doses of from 4 to 6 ounces dissolved in one or two seers of Cow's Milk-Cow's Milk adds considerably to the power of the medicine. Of Calomel $\frac{1}{2}$ an ounce is a full dose given in a ball. It is a more certain aperient than the Aloes owing to the variable quality of the latter-in all inflammatory affections it is the aperient which ought to be used.

I have tried the effect of Epsom and Glauber Salts, each separately, to the extent of 3 or 4 pounds for a dose and repeated it on consecutive days, but without any aperient effect. The same is to be said of Ghee, and of Castor Oil in doses each separately exhibited of a bottle-fuil. What is somewhat 
remarkable Croton Oil seeds which prove so efficacious a purgative for the Elephant in ounce doses, have, when to the extent of an ounce, morning and evening, produced no apparent or other visible effect. Thinking that a much smaller dose of this medicine than what is required to move the Elephant would be efficacious in the Camel. I commenced with a drachm of it-no effect-two drachms were given in the morning of the following day-then at 11 A. M. and 4 P. M, on each occasions a drachm. On the 3rd day a drachm, morning and evening, were given. On the 4th day half an ounce morning and evening, but without any apparent effect. An ounce, or at most an ounce and a half of the pulverized seeds, will freely purge the Elephant within the $\mathbf{2 4}$ hours.

Common Salt also appears inert as a purgative to the Camel. I have given it in doses to the extent of a pound.

Enemata do not appear to act on the bowels of the Camel-one consisting amongst others of a gallon and a half of water, a pound of common Salt and $\mathbf{a}$ pint of Castor Oil had no effect.

\section{TONICS.}

The Margoosa Bark and Milky-juice of the Madaar, are given with advantage for this purpose, in Mussals, for which Native recipes are given below.

SUBJOINED ARE NATIVE RECEIPTS, \&c. \&c.

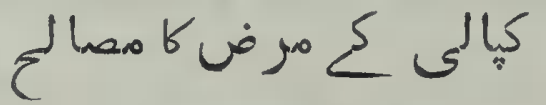

FOR KUPPALEE-KA MURZ.

MUSSAL No. 1.

No. 1. LAPE, OR OINTMENT.

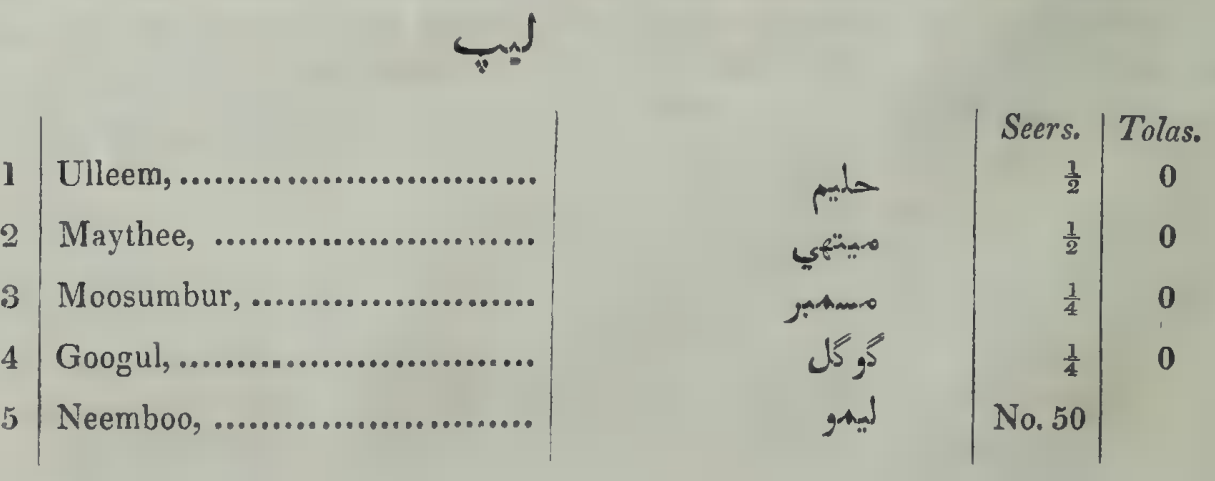


Nos. 1 to 4 to be finely powdered and mixed with juice of the Limes, and a small quantity of water to be added; then boil until formed in the consistency of Ointrnent and apply over the part affected.

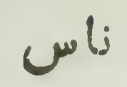

No. 1. NAHASS, OR SNUFF.

For the Same.

\begin{tabular}{|c|c|c|c|c|}
\hline & & & Seers. & Tolahs. \\
\hline 1 & Summundurpul, .................. & سمهند ر ريله & 0 & 2 \\
\hline 2 & Puttukdee, $\quad$......................... & & 0 & 3 \\
\hline 3 & Maendpul,........................... & ميند بريل & 0 & 3 \\
\hline 4 & Kaephul, ,........................ & كاني برئل & 0 & 3 \\
\hline 5 & Peepla Mohde, .................. & & 0 & 3 \\
\hline 6 & Lavung,............................. & & 0 & 3 \\
\hline 7 & Hing,.................................. & & 0 & 3 \\
\hline
\end{tabular}

These to be very finely powdered and divided into three parts : one of which to be blown into nostrils, and repeated night and morning till discharge of mucus disappears.

\section{MUSSAL No. 1. TO BE GIVEN INTERNALLY.}

\section{For the SaMe.}
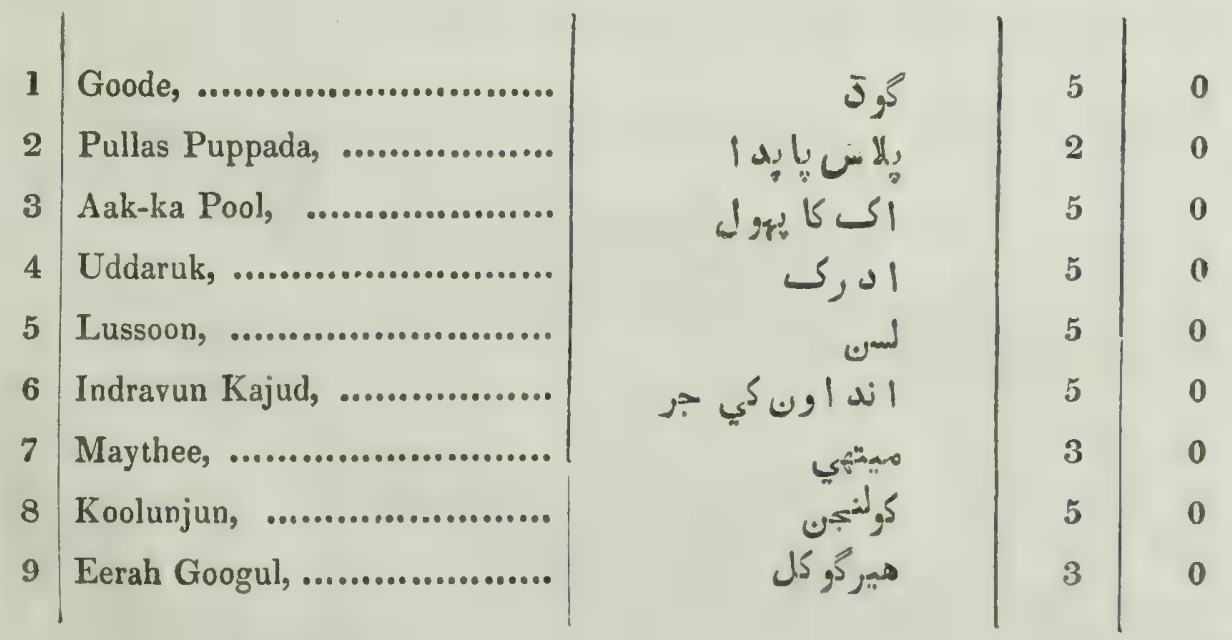

The whole to be well pounded together and a sufficient quantity of Country Arrack to be added, as will form into boluses of the size of an Orange. One of which to be given morning and evening for three days-after which to be repeated daily. 
If the Lape, Nahass and Mussal given above, produce no good effect, the undermentioned may be used.

No. 1. LAPE, OR OINTMENT.

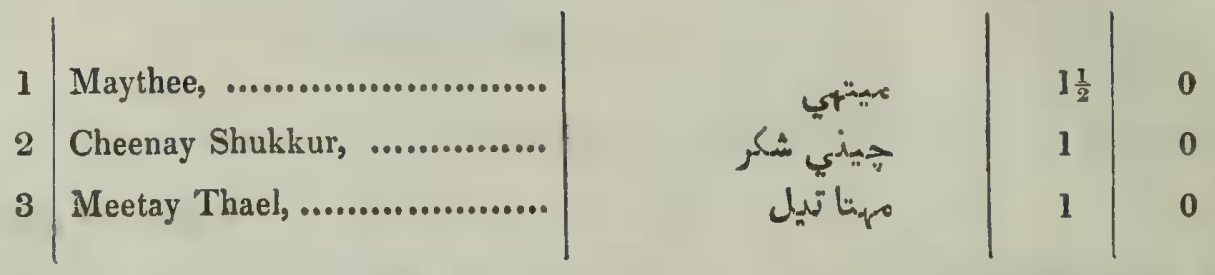

No. 1. To be well powdered and mixed with Nos. 2 and 3, adding a small quantity of water as will form it into an Ointment-these to be boiled and applied warm to the tumour.

No. 2. LAPE, OR OINTMENT.

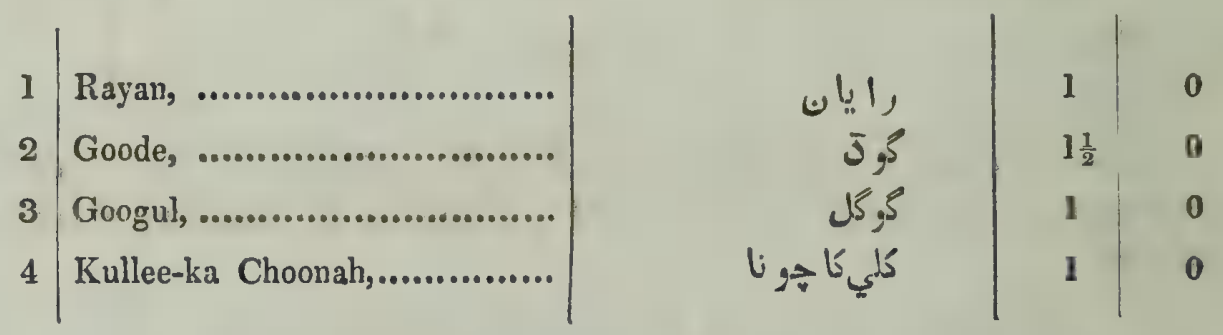

The whole to be well grounded, adding a small quantity of Arrack gradually to form into a consistency of Ointment, of which a small quantity to be applied over the tumour; afterwards a heated bratty to be held near till it is quite dry.

\section{NAHASS, OR SNUFF.}

This to be used simultaneously with the Lape.
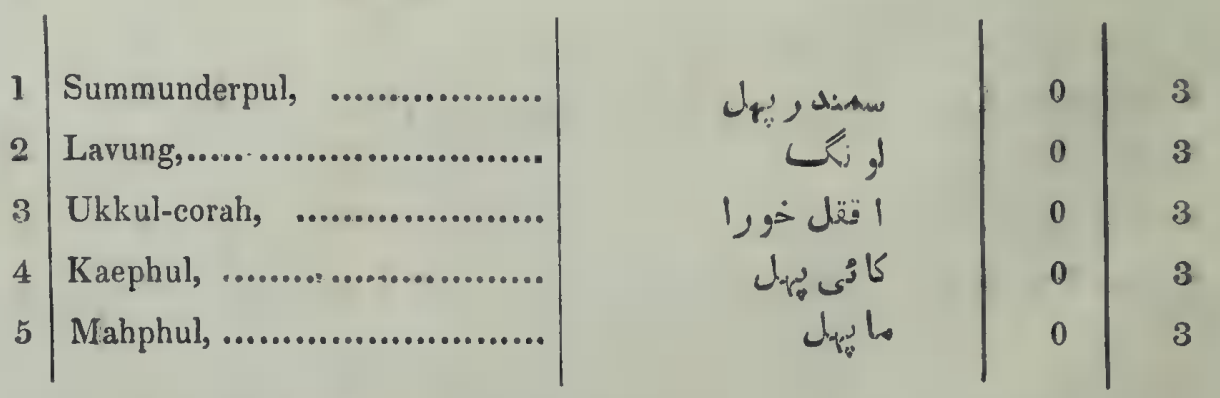

The whole to be well powdered and blown into the nostrils. To be continued till the discharge stops. The following Mussal to be given at the same time internally. 


\section{( 31$)$}

\section{MUSSAL。}

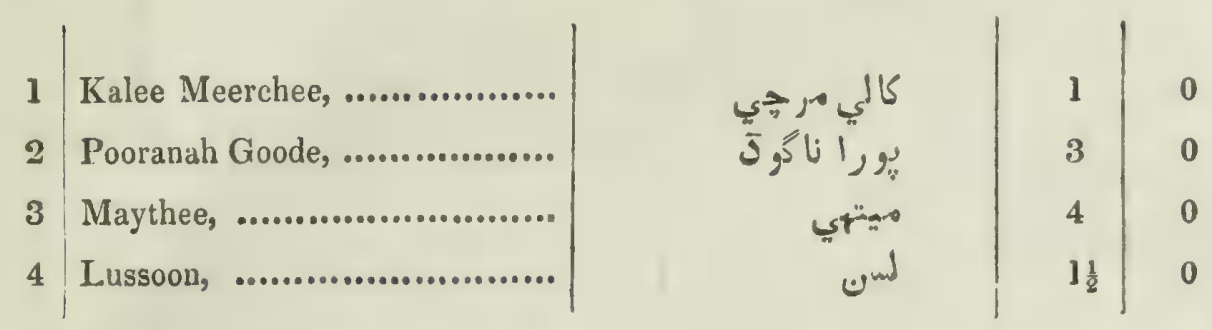

The whole to be pounded well, adding a sufficient quantity of Arrack so as to form it into a mass, and boluses of the size of an Orange to be made, one of which to be given night and morning for three days successively, afterwards give one every morning.

\section{BHAO-KA MURZ.}

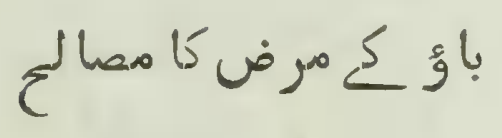

MUSSAL No. 1.

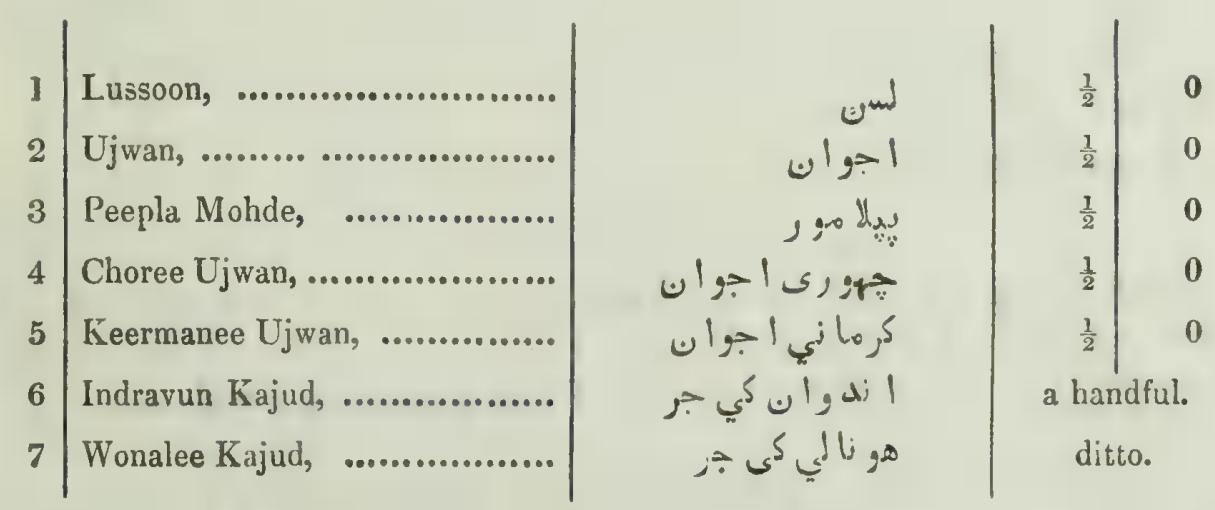

Nos. 2, 3, 4 and 5 to be powdered. Nos. 1, 6 and 7 well pounded. The whole to be mixed together and formed into boluses of size of an Orange each, of which give one every $2 \mathrm{~d}$ or $3 \mathrm{~d}$ hour. To commence soon.

\section{A NOTHER No. 2.}
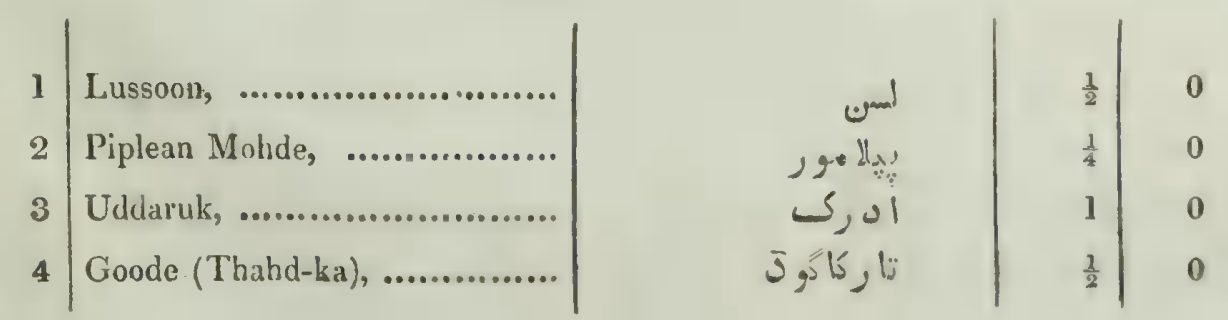

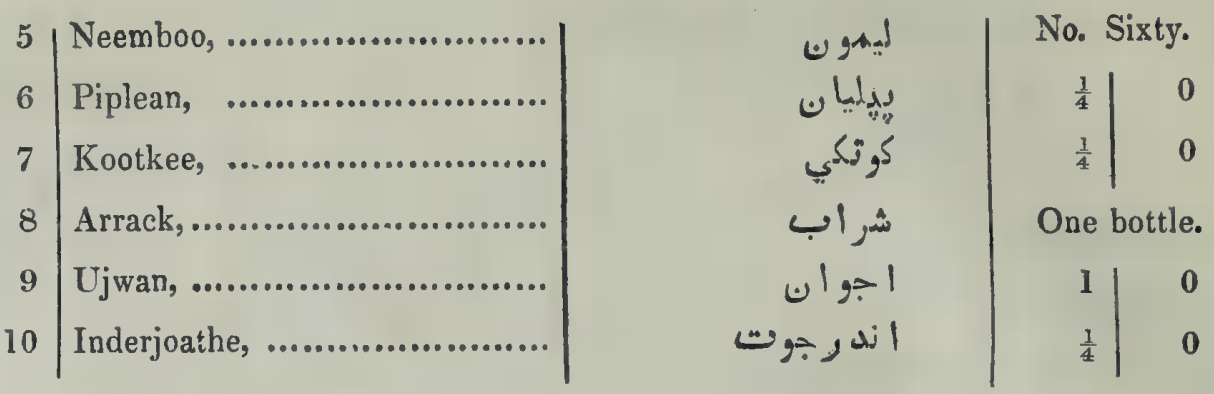

Nos. 6, 7, 9 and 10 to be powdered. Nos. 1, 2 and 3 to be well pounded-the juice of No. 5 to be added and well mixed; then add No. 8. Now divide into two doses, one of which give immediately, and the other to be repeated, if necessary, after $2 \mathrm{~d}$ or $3 \mathrm{~d}$ hour.

ANOTHER No. 3.
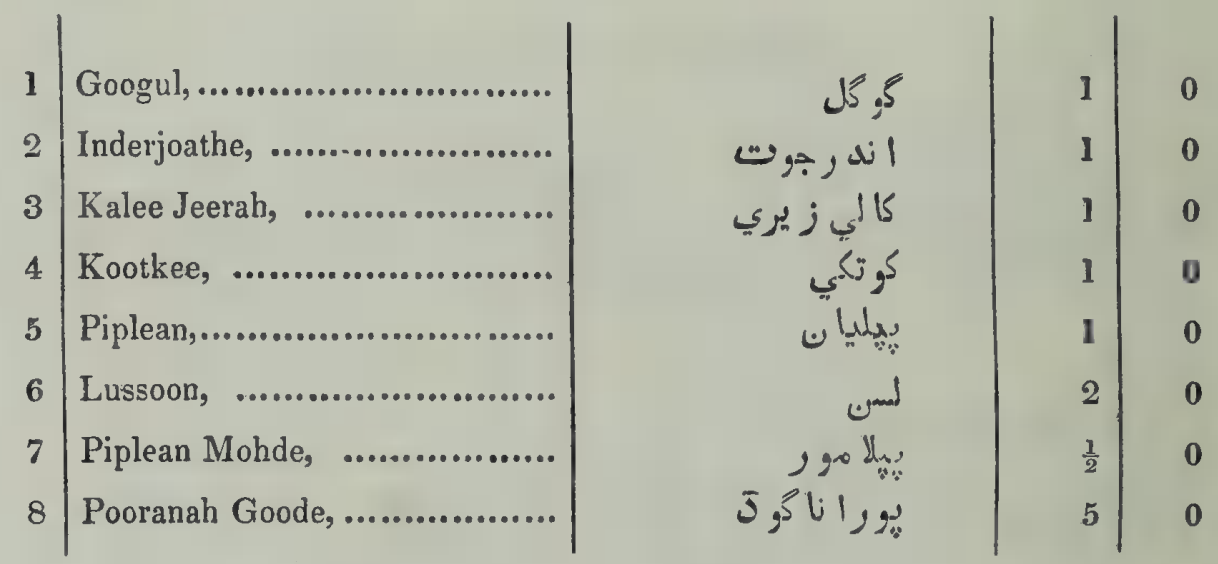

Nos. 1, 2, 3, 4, 5 and 7 to be pulverized. Nos. 6 and 8 to be pounded, and added to 3 bottles of Arrack, the whole to be well mixed and formed into boluses of the size of an Orange each-one of which to be given every second hour.

\section{UNJUN, OR APPLICATION FOR THE EYES.}<smiles>[In]=[Te]</smiles>

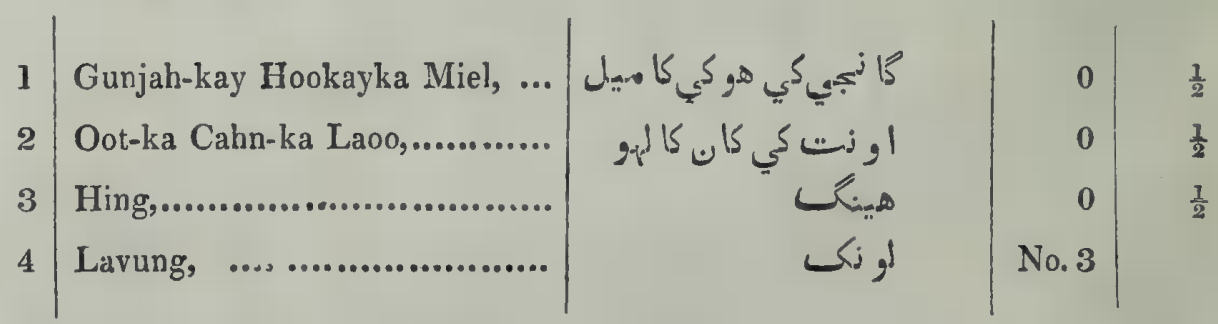

The above to be finely pulverized and mixed together with a small quantity of lime juice, and to be applied to the lids of the Camel's eyes. 


\section{$(33)$}

\section{KOOD-KA MURZ:}

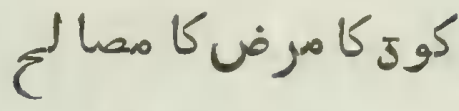

MUSSAL No. 1.
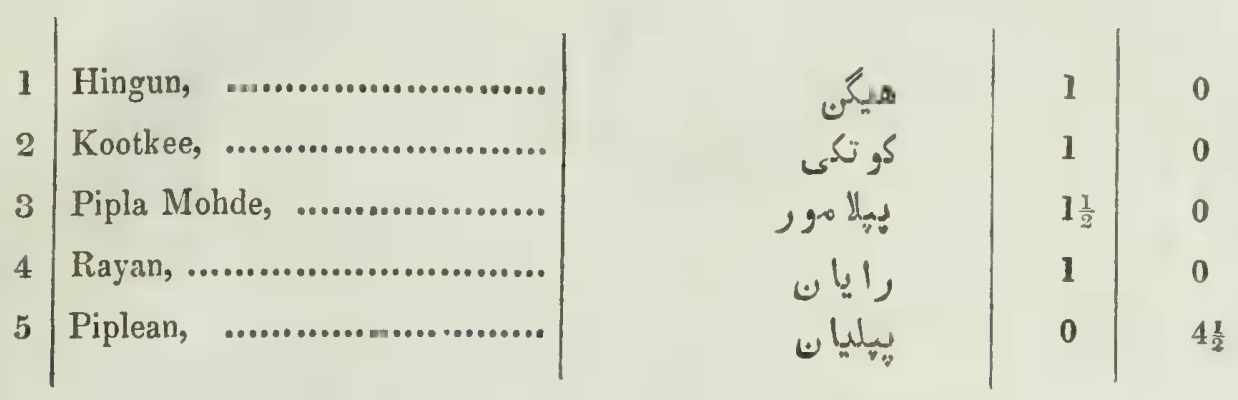

The above to be well powdered and .mixed with a sufficient quantity of Jaggery to form into a mass, then divide into seven boluses, of which give one every morning.

MUSSAL No. 2.

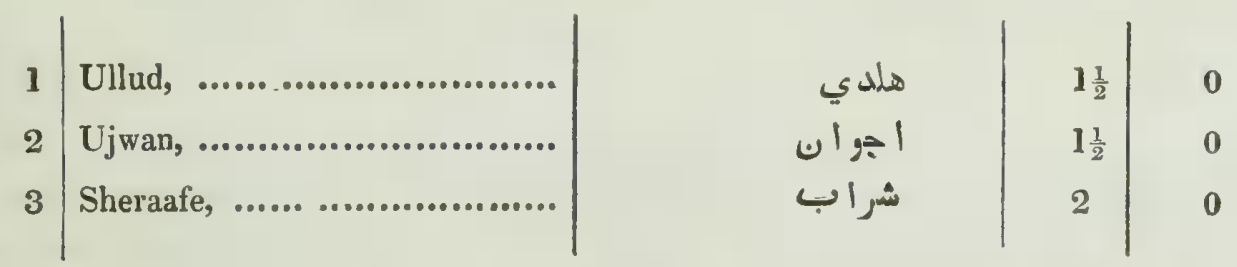

Steep Nos. 1 and 2 in No. 3 for a whole night, and divide into three parts, one of which give every morning for three days.

MUSSAL No. 3.

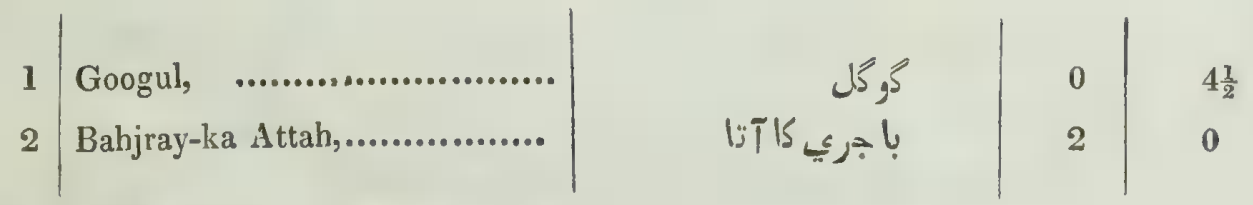

These to be divided into three parts-One part of which No. 2 to be made into a mass with a little water-a third part of No. 1 to be added to a third part of No. 2, and baked and given every evening. To be continued for three days.

\section{NAHASS, OR SNUFF.}

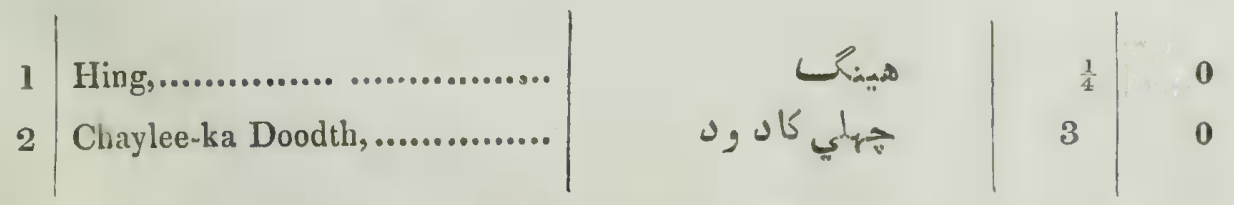

No. 1 to be pulverized and mixed with No. 2 and then pour into the nostrils. 
SOOLFA-KA MURZ.

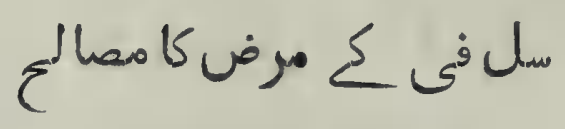

MUSSAL No. 1 .
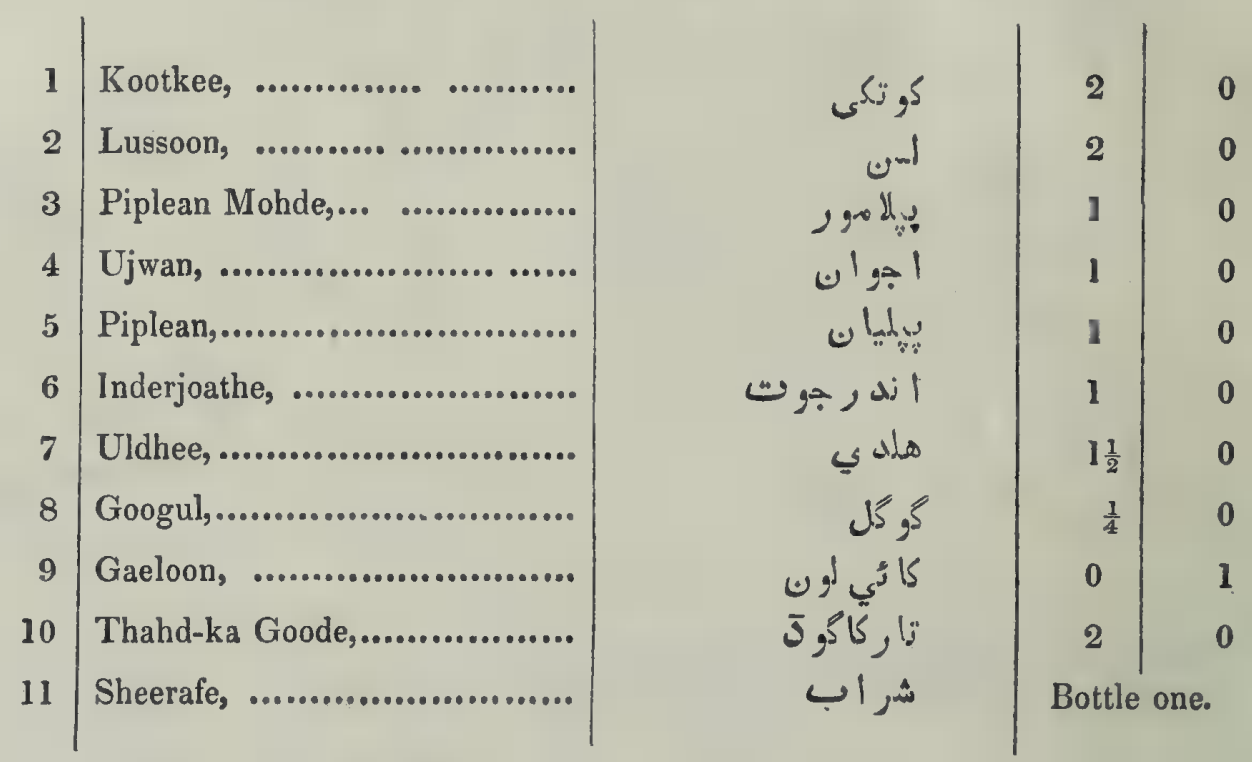

Nos. $1,2,3,4,5,6,7,8$ and 9 to be pulverized, then add No. 10 and mix with No. 11 and divide into three parts. Give one part every morning for three successive days.

\section{NAHASS, OR SNUFF.}

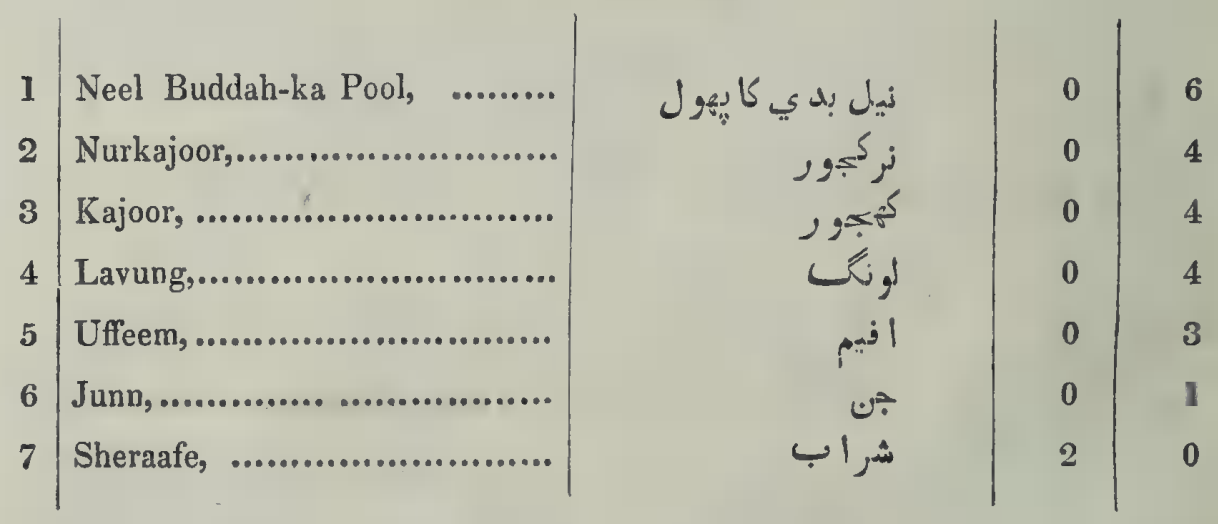

Nos. $1,2,3,4,5$ and 6 to be finely pulverized and mix with No. 7 , then pour the mixture into both nostrils. 


\section{MOORGHEE-KA MURZ.}

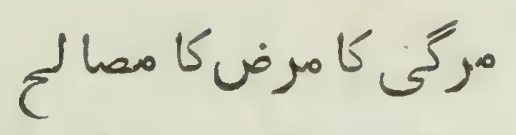

MUSSAL No. 1.

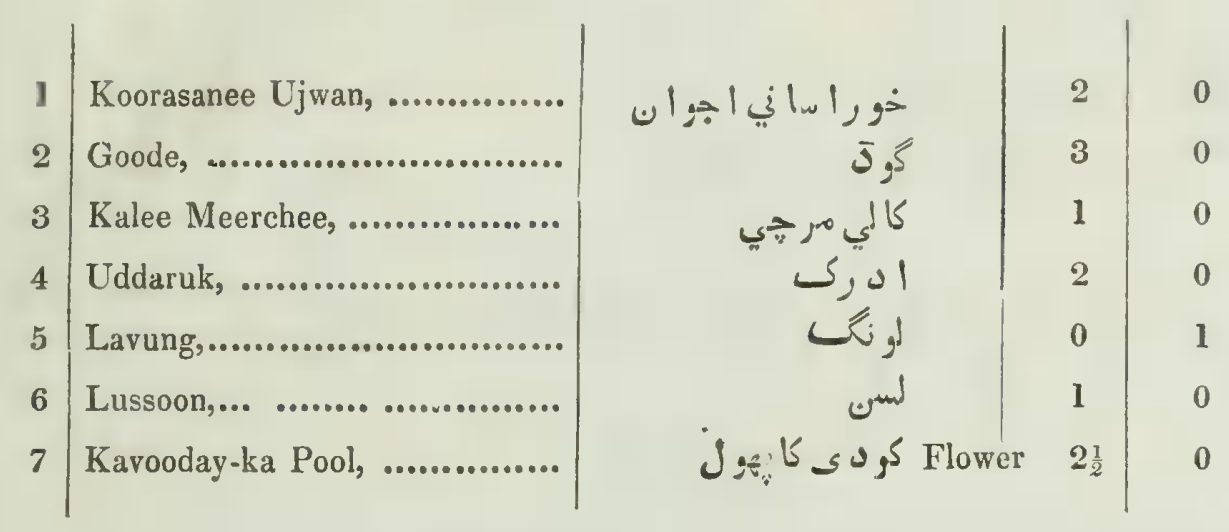

These to be powdered and a sufficient quantity of Brandy added to form into a mass and divide into three boluses. Give one every morning for three successive days.

ANOTHER No. 2.
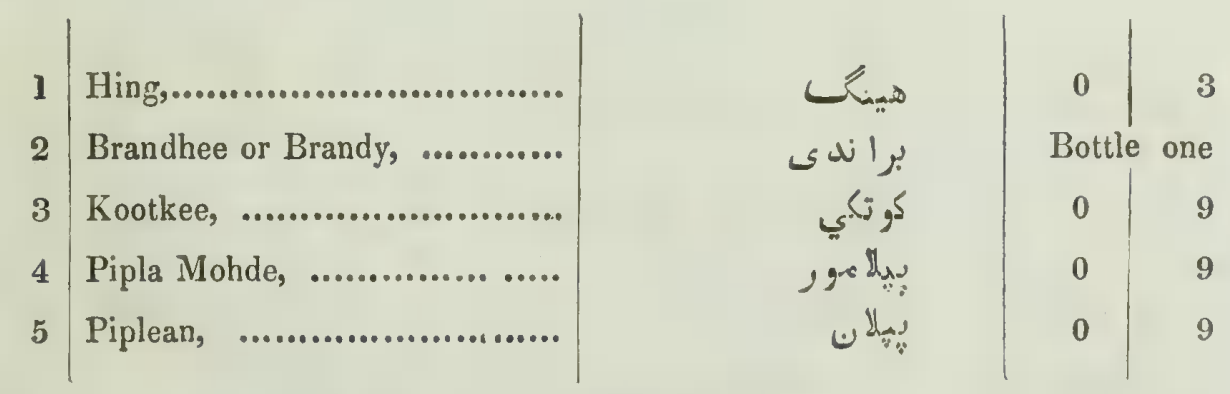

The substances to be finely powdered, the Brandy to be then added, and the mass divided into three parts. Of which give one every morning for three successive days.

ANOTHER No. 3.

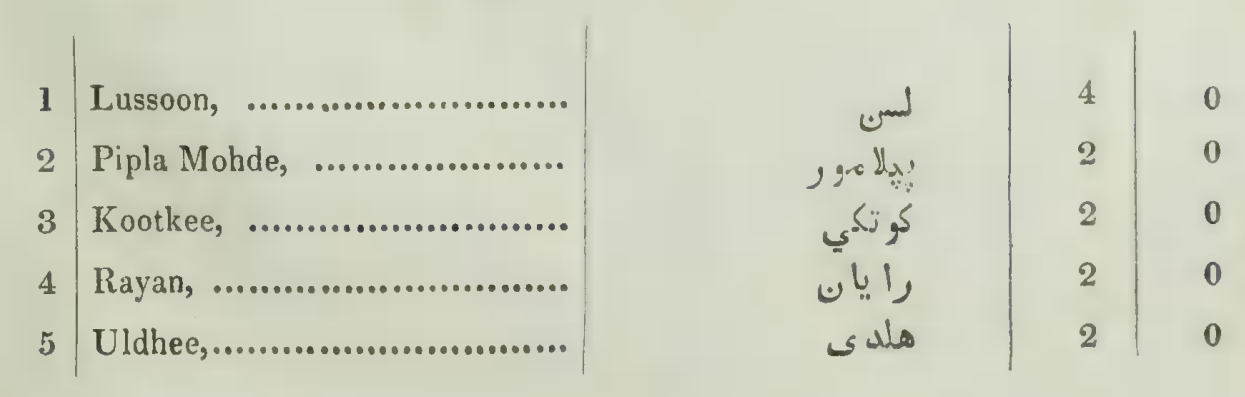




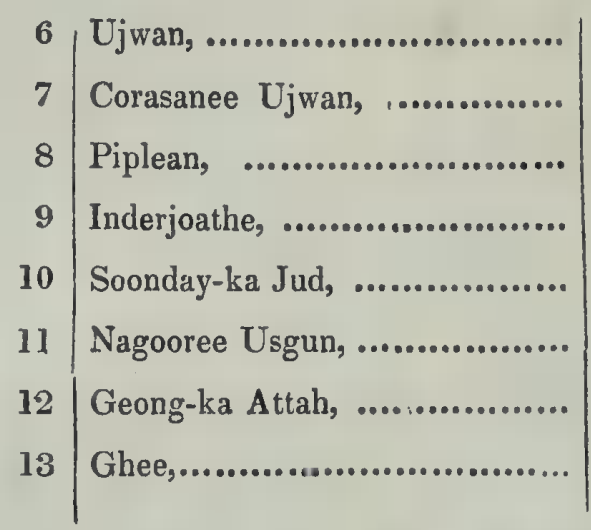

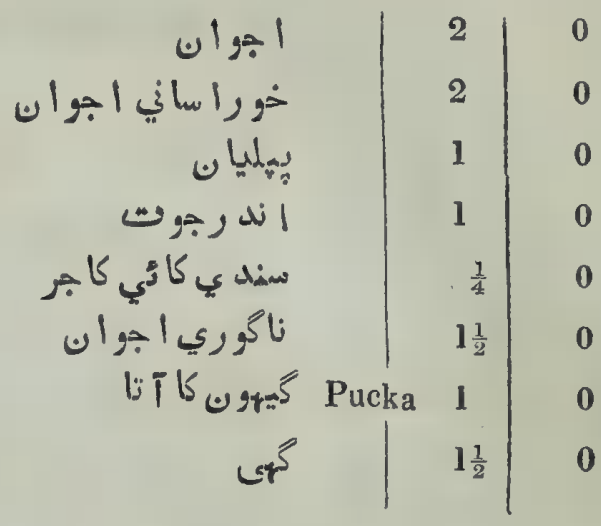

The whole to be well pounded together and formed into a mass, then divide into 14 boluses-of which give one morning and evening for seven successive days.

\section{NAHASS, OR SNUFF. ناس}

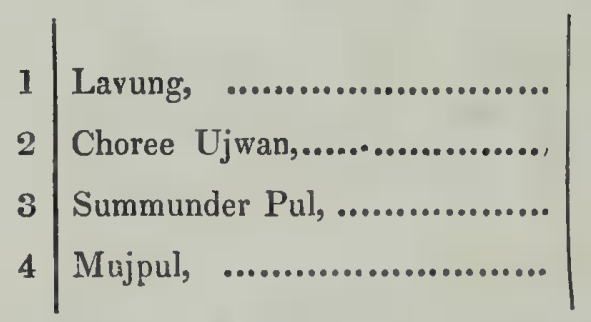

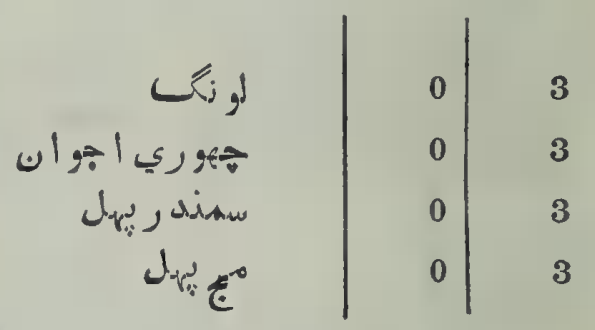

These to be finely pulverized and divided into three parts, one of which to be blown into the nostrils every morning for three days.

NAHASS, OR SNUFF.

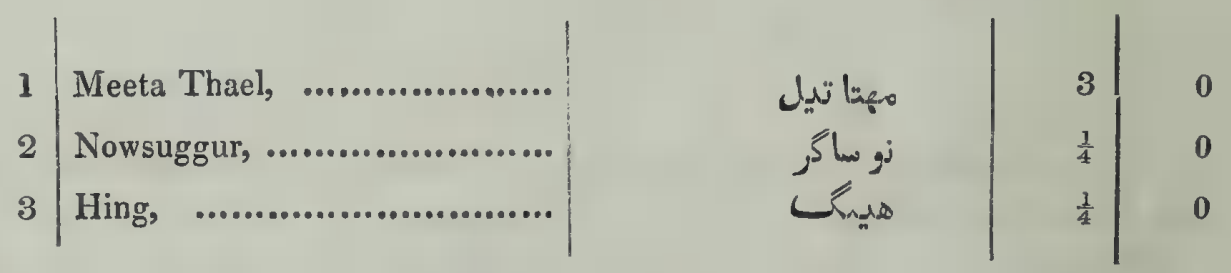

Nos. 2 and 3 to be finely powdered and mixed with the Oil. One-third of which to be poured into the nostrils and repeated for three successive days. 


\section{ZAARBAHD-KA MURZ.}

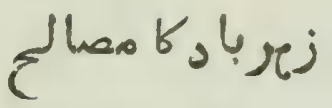

MUSSAL No. 1.
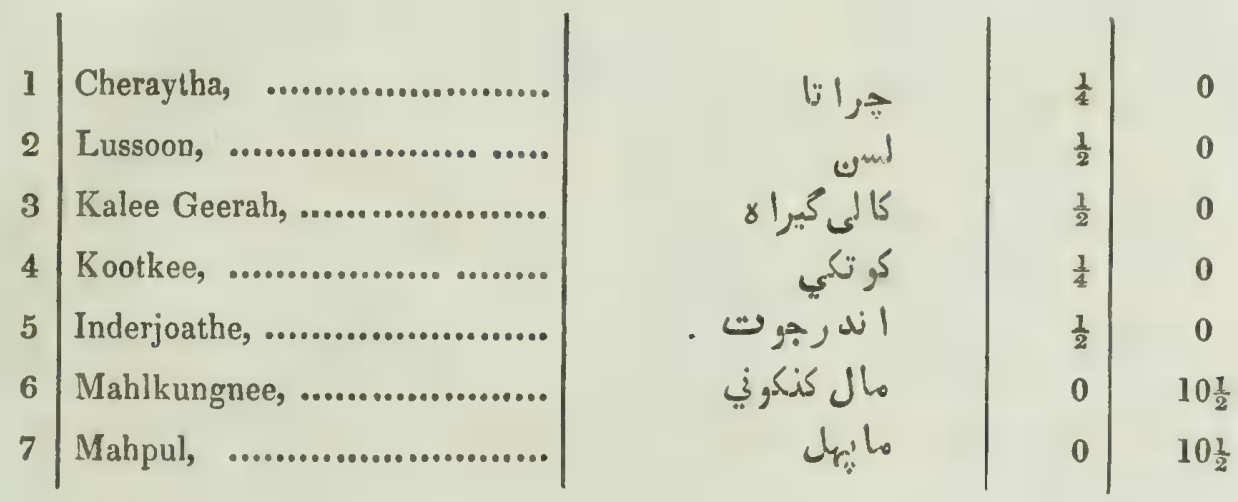

The whole to be finely powdered and mixed with a sufficient quantity of Arrack and divided into six boluses, of which give one morning and evening.

ANOTHER No. 2.

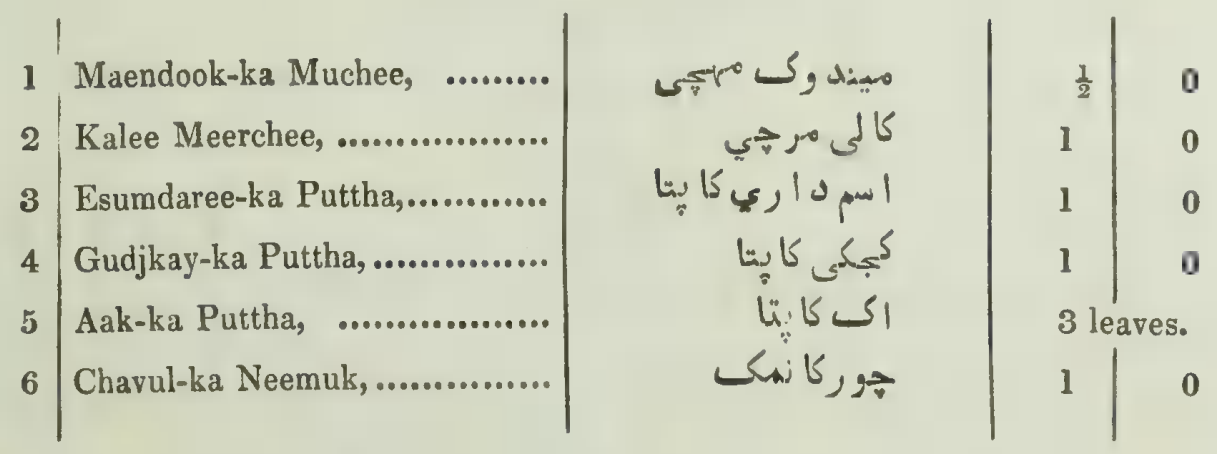

The whole to be well pounded, adding a small quantity of Honey to form into a mass, and divide into 6 boluses, of which give one moruing and evening.

ANOTHER No. 3.
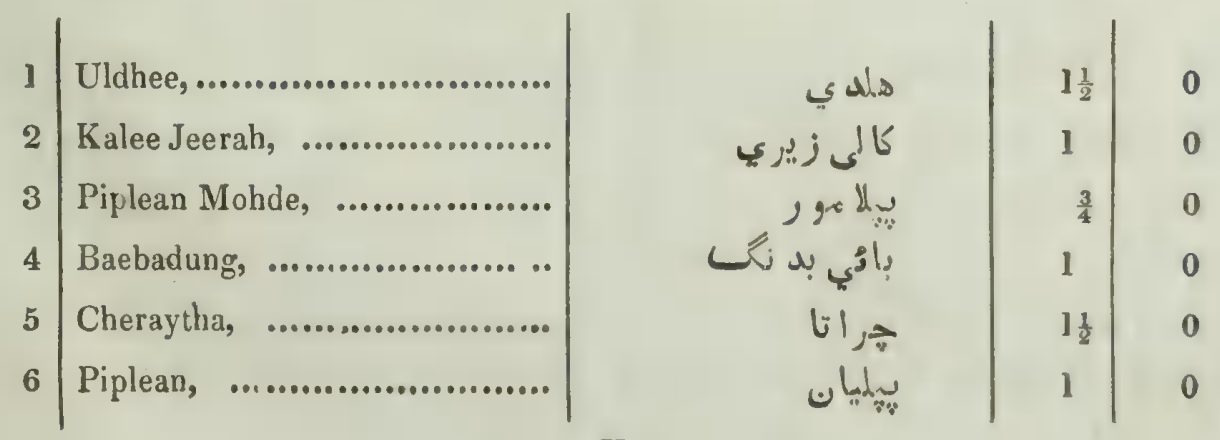


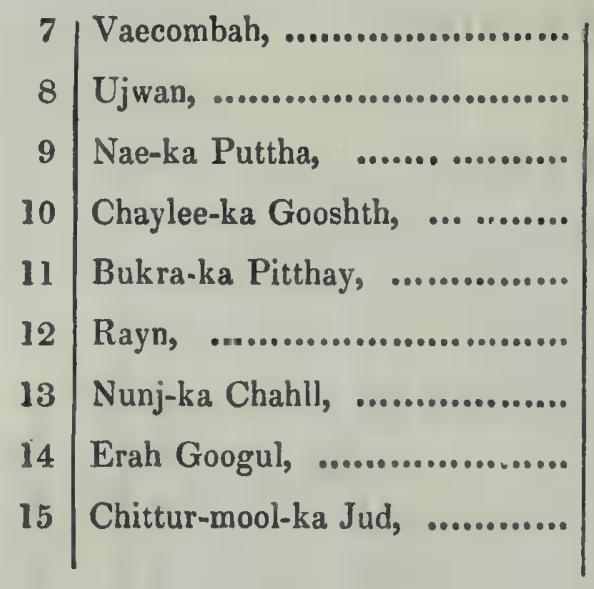

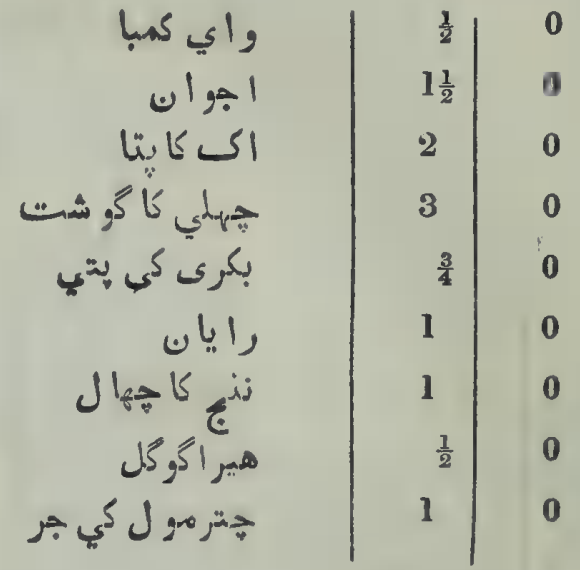

The substances $1,2,3,4,5,6,7,8,12,13,14$, and 15 to be separately powdered. No. 10 to be properly picked and add No. 9 with a sufficient quantity of Arrack to form into a mass, divide into 14 boluses, of which give one every morning.

\section{CUMMAUN-KA MURZ.}

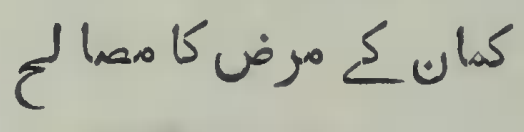

MUSSAL No. 1.
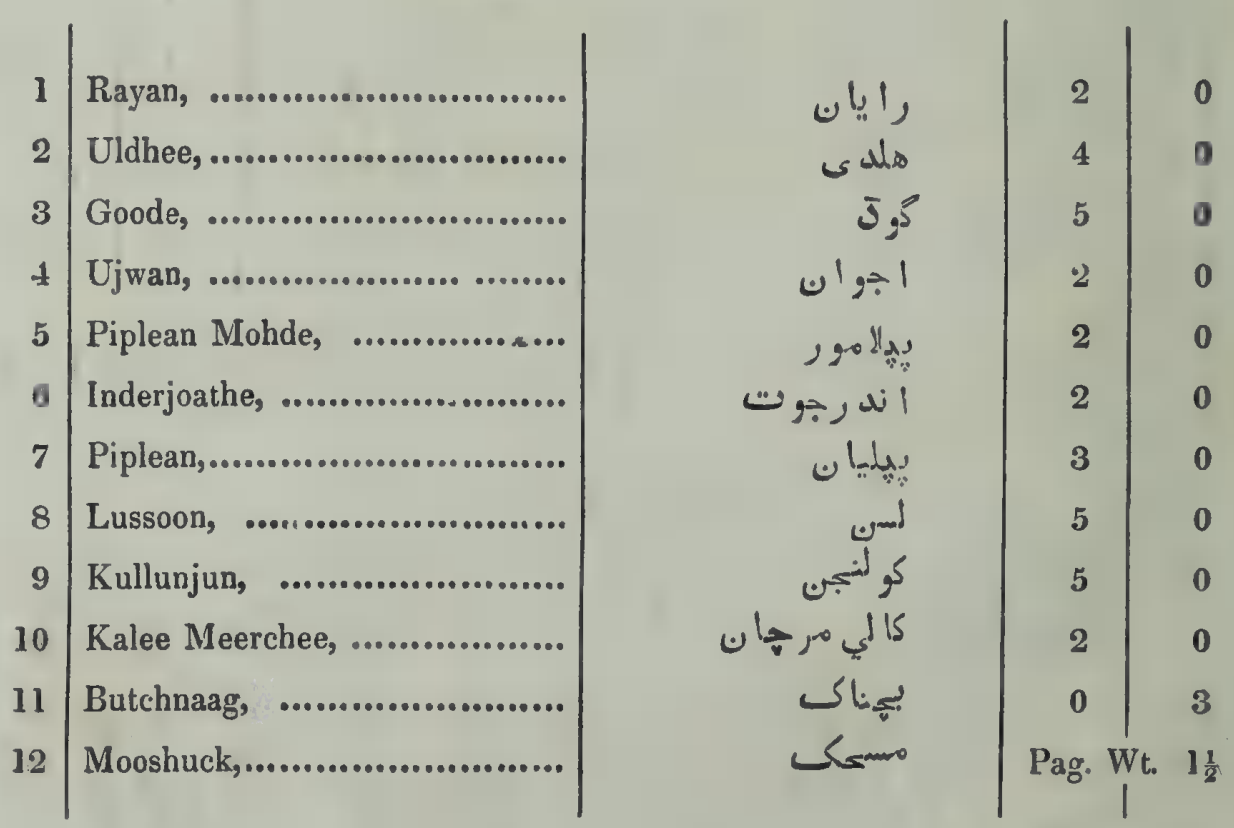

The above to be finely pulverized and a sufficient quantity of Arrack added to form a mass, which divide into boluses of size of an Orange, of which give one every morning. 
MUSSAL No. 2.

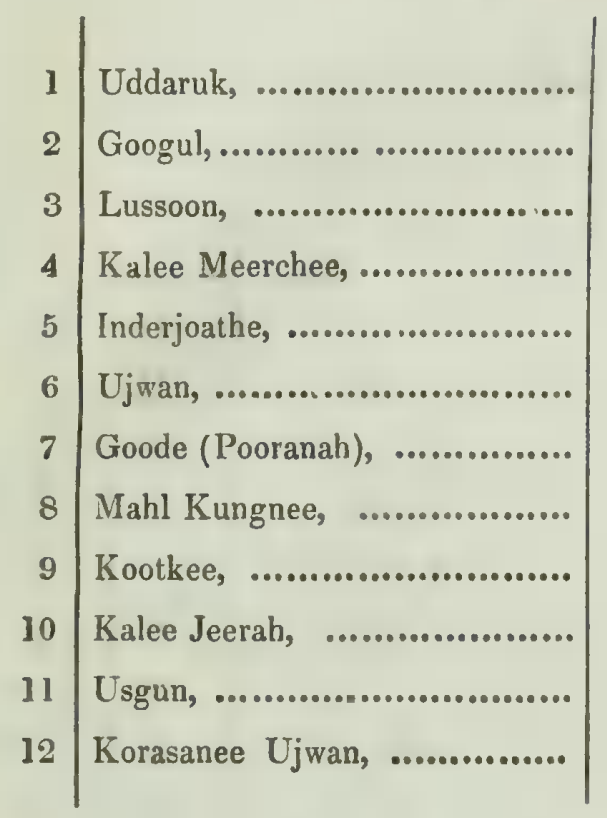

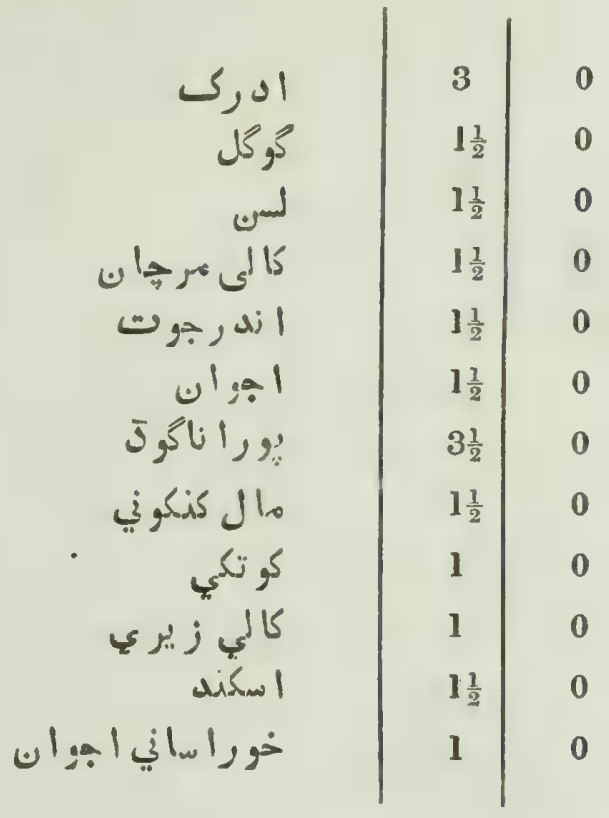

The whole to be finely powdered and formed into a mass with sufficient quantity of water and divide into 14 boluses. Give one morning and evening for three successive days-afterwards give one every morning.

\section{JOWLAH, OR LUCKWA.}

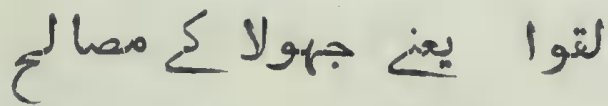

MUSSAL No. 1.

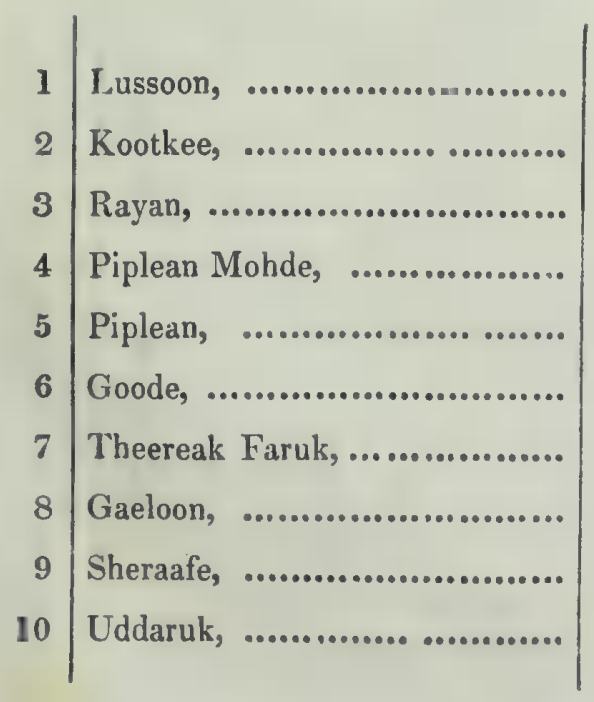

\begin{tabular}{|c|c|}
\hline لسم & 3 \\
\hline كو تكي & $1 \frac{1}{2}$ \\
\hline & 2 \\
\hline يهيله مور & $1 \frac{1}{2}$ \\
\hline & 1 \\
\hline 5,3 & 4 \\
\hline تر يا فرت & 0 \\
\hline كانى لون & 0 \\
\hline شراب اب & 3 \\
\hline 1 & 2 \\
\hline
\end{tabular}


The substances to be finely pulverized and added to the Arrack, and divided into boluses of size of un Orange, of which give one every morning.

MUSSAL No. 2.
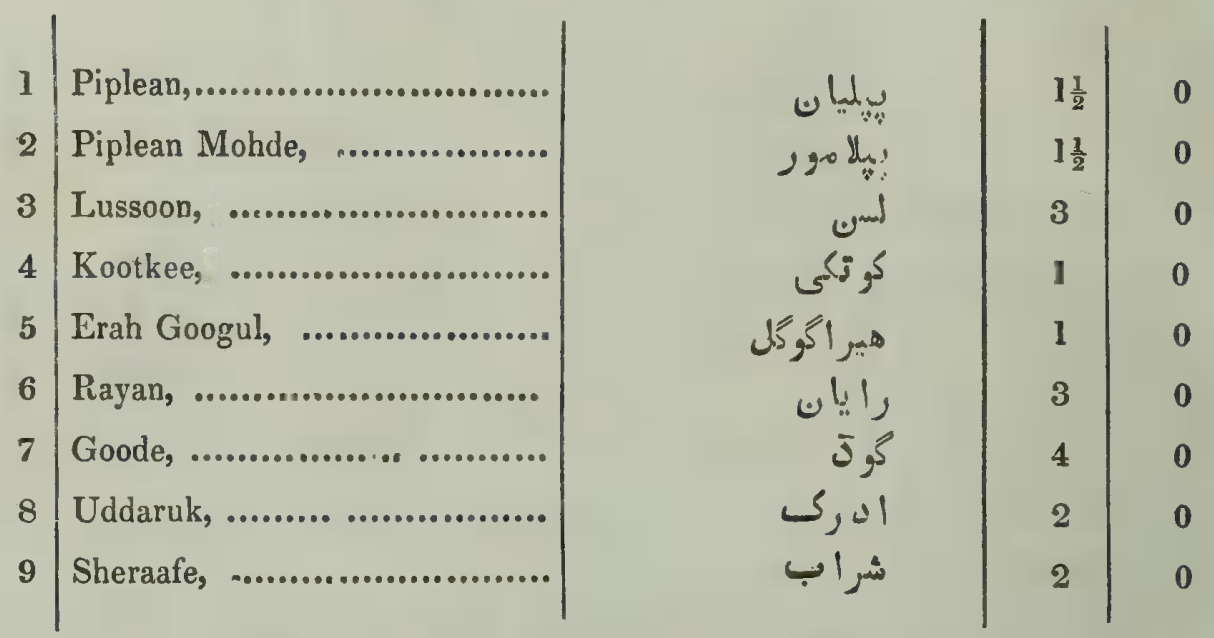

The substances to be finely pulverized, then mix with the Arrack and form into $\mathrm{a}$ mass, which divide into boluses of size of an Orange-give one every morning.

\section{PAPRA, OR PAEPSA.}

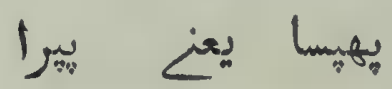

MUSSAL No. 1.

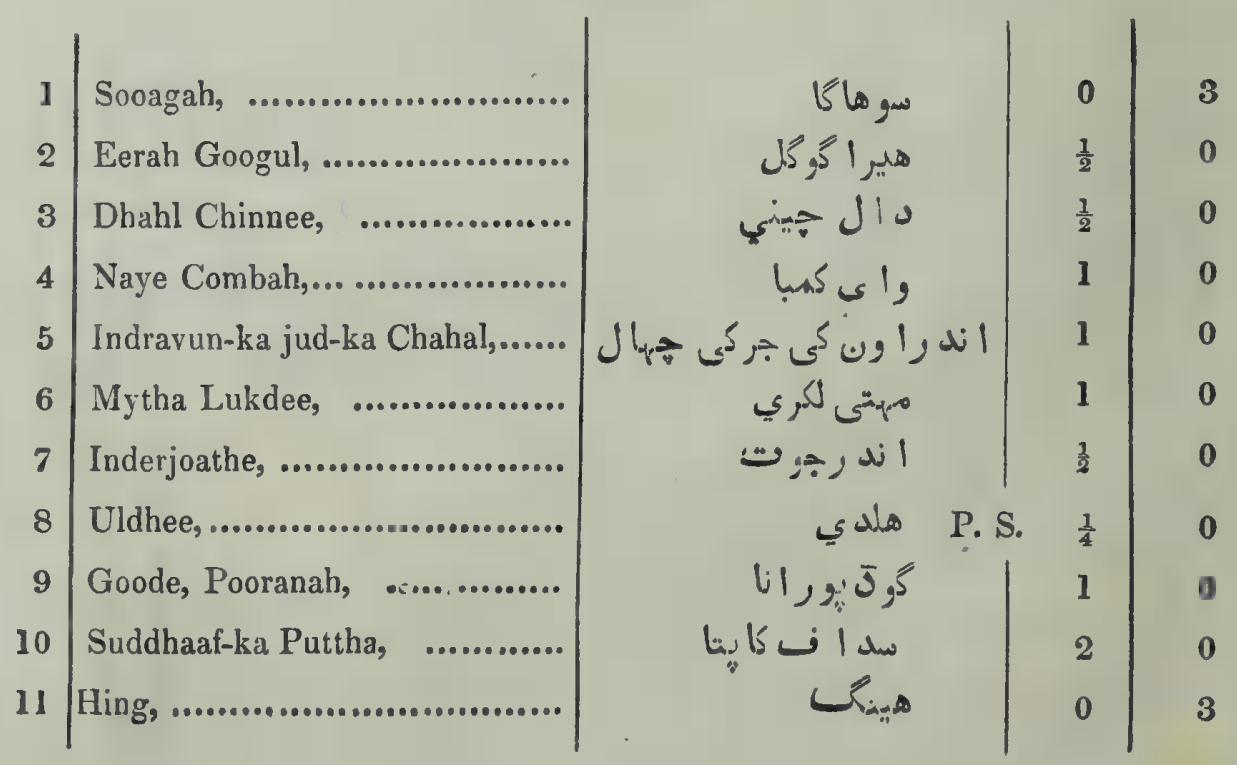




\section{$(41)$}

The substances to be powdered and formed into a mass, which divide into boluses of size of an orange, of which give one every morning.

MUSSAL No. 2.
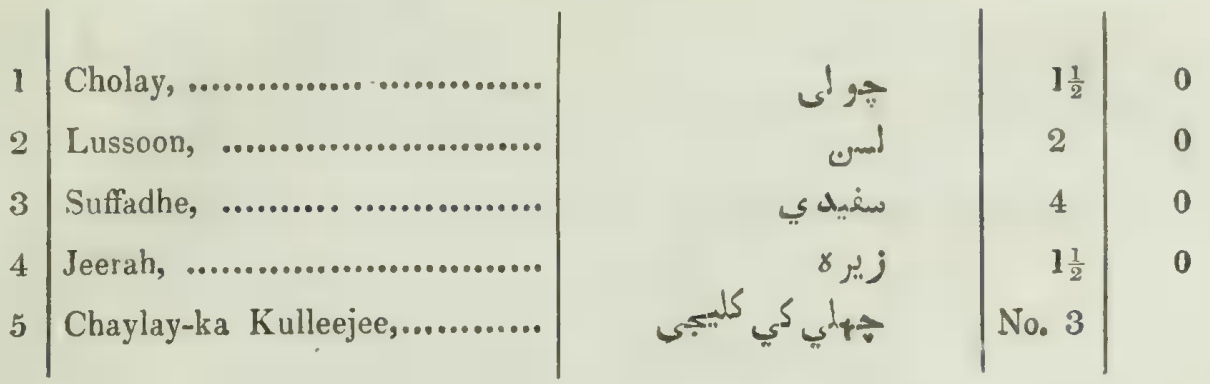

The substances to be finely pulverized, the others to be cut in pieces and pounded together and divided into seven boluses, of which give one every morning.

MUSSAL No. 3.
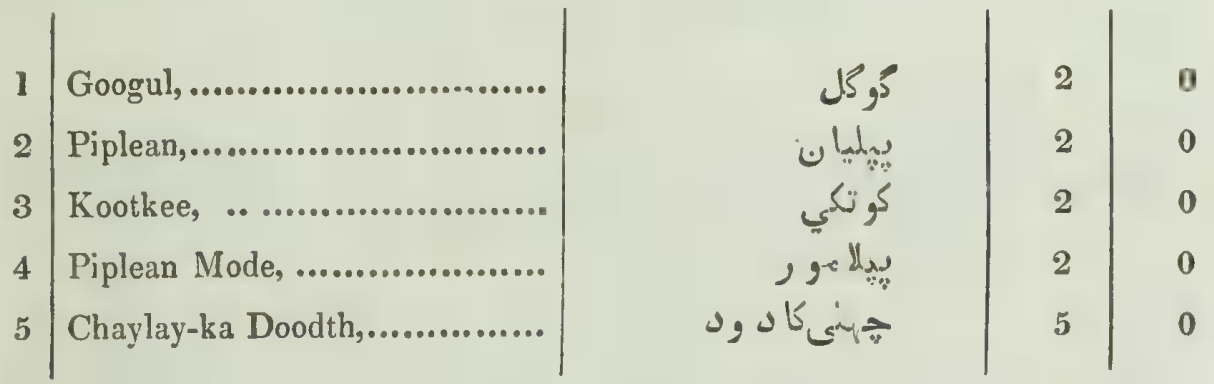

Nos. 1 and 5 to be boiled together till reduced to 2 seers, then add Nos. 2, 3 and 4 previously pounded, which divided into five parts-one of which give every morning.

\section{CHOODEE-KA MURZ.}

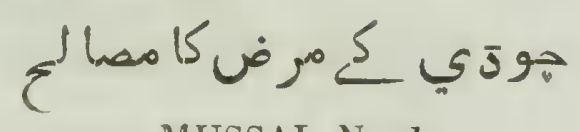

MUSSAL No. 1.

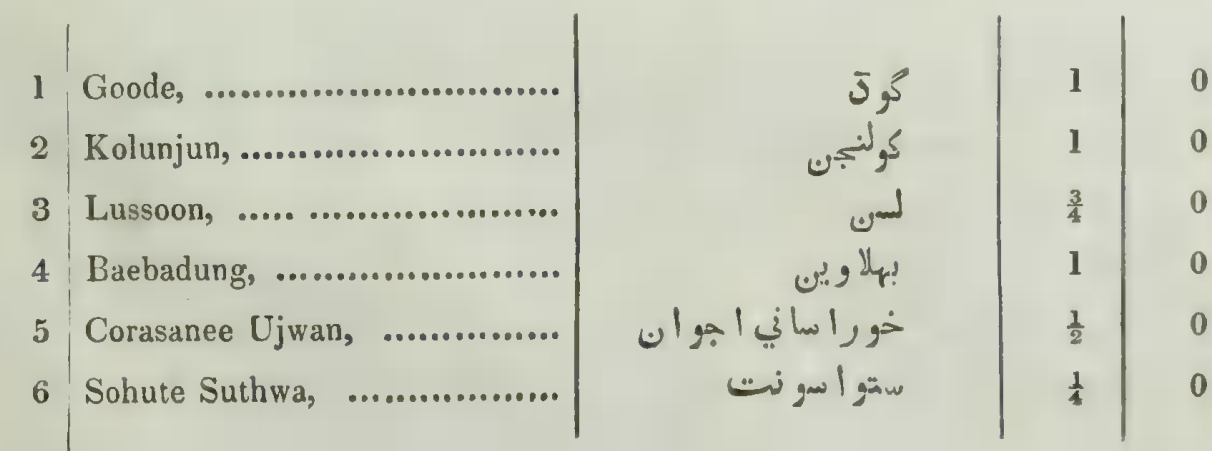


The substances to be well pounded together, adding a sufficient quantity of Arrack to form a mass and divide into three parts, of which give one every morning.

The head and trunk to be well fomented with the following Decoction:

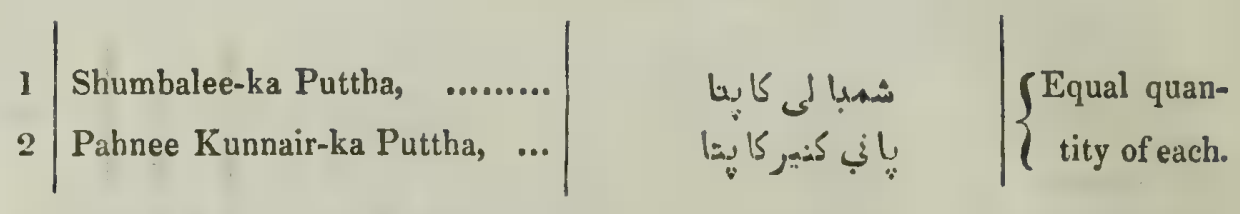

To be boiled down with 2 gallons of water.

SOALE, OR MALOLE.

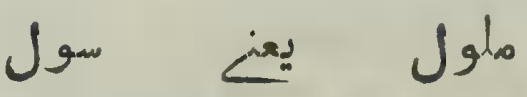

MUSSAL No. 1.

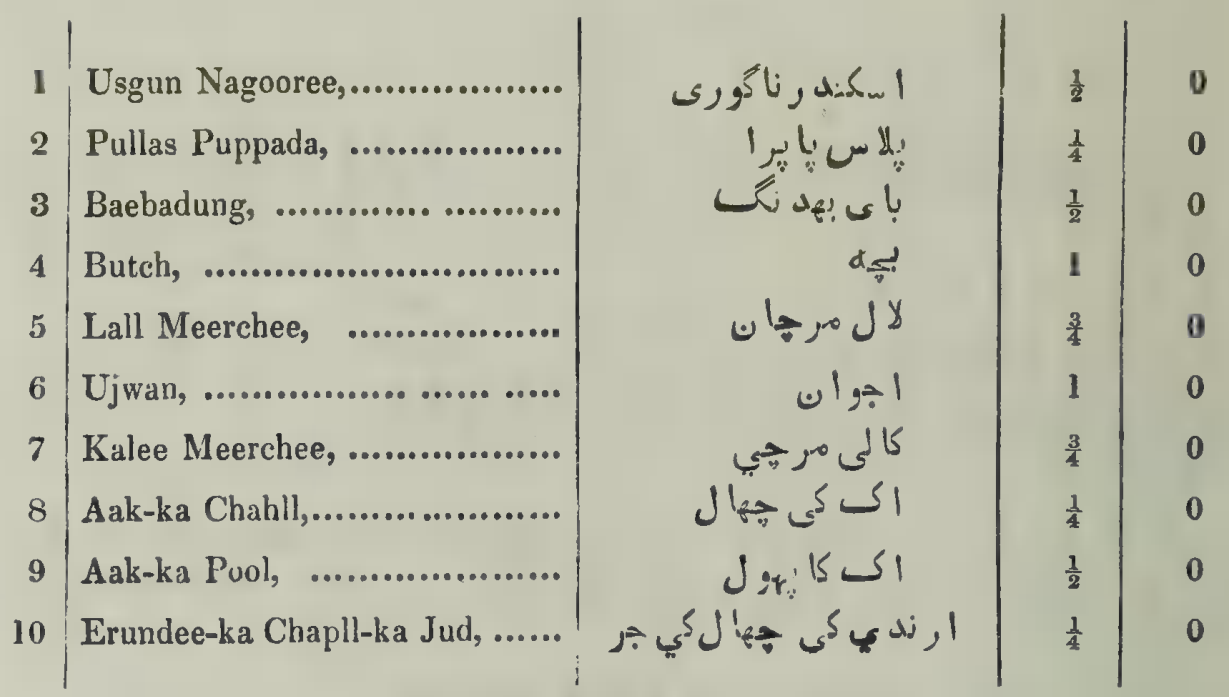

The whole to be well pounded together with a sufficient quantity of water so as to form it into a mass and divide into three boluses-one of which to be given every second hour.

MUSSAL No. 2.

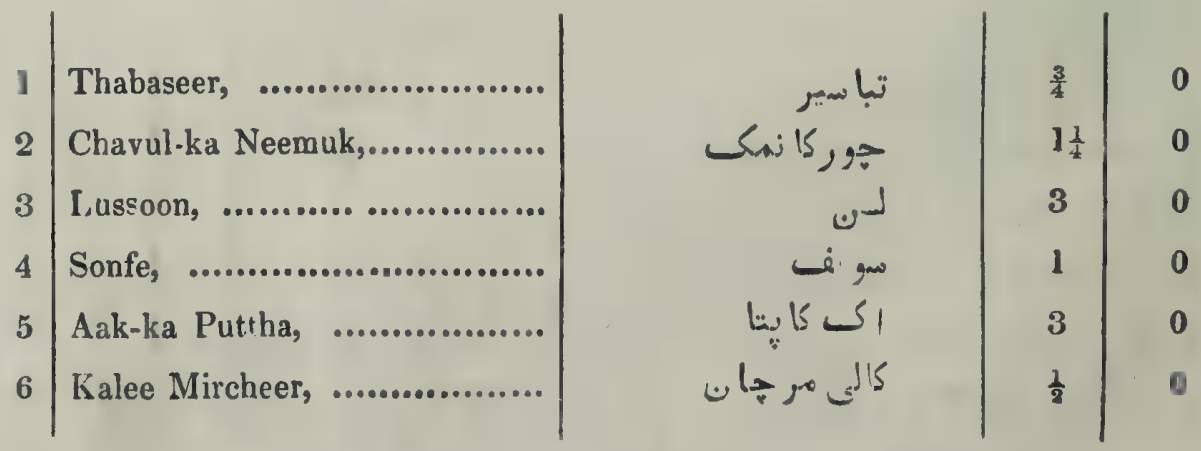




\section{$(43)$}

Nos. 2, 3, and 5 to be boiled in 3 seers of water till reduced to one seer; and give to animal-afterwards the Nos. 1,4 and 6 to be pounded and given.

MUSSAL No. 3.

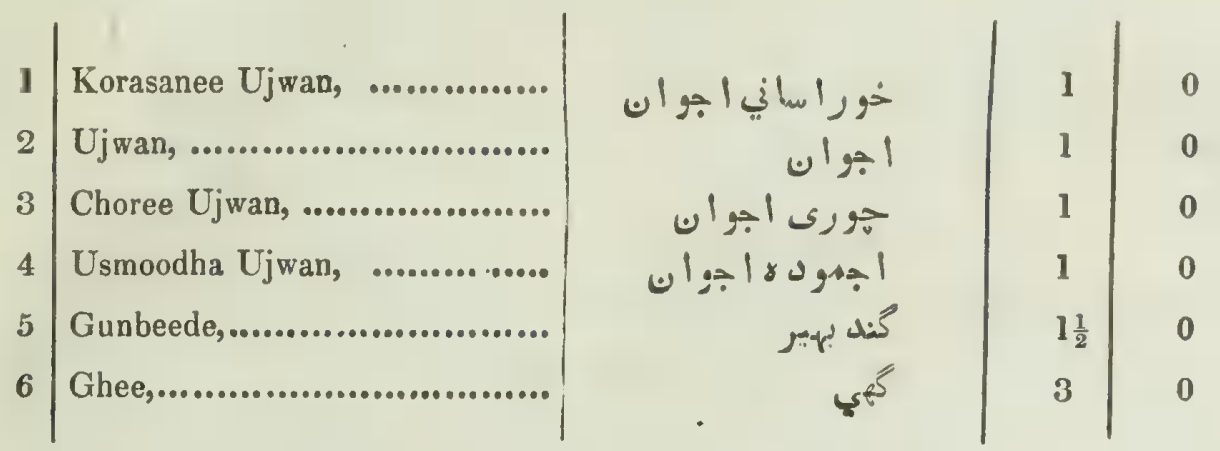

The whole to be boiled in two seers of water and given to animal.

\section{SOOZAAK-KA MURZ.}

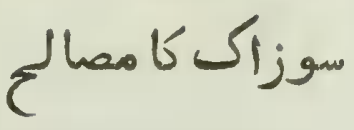

MUSSAL No. 1 .
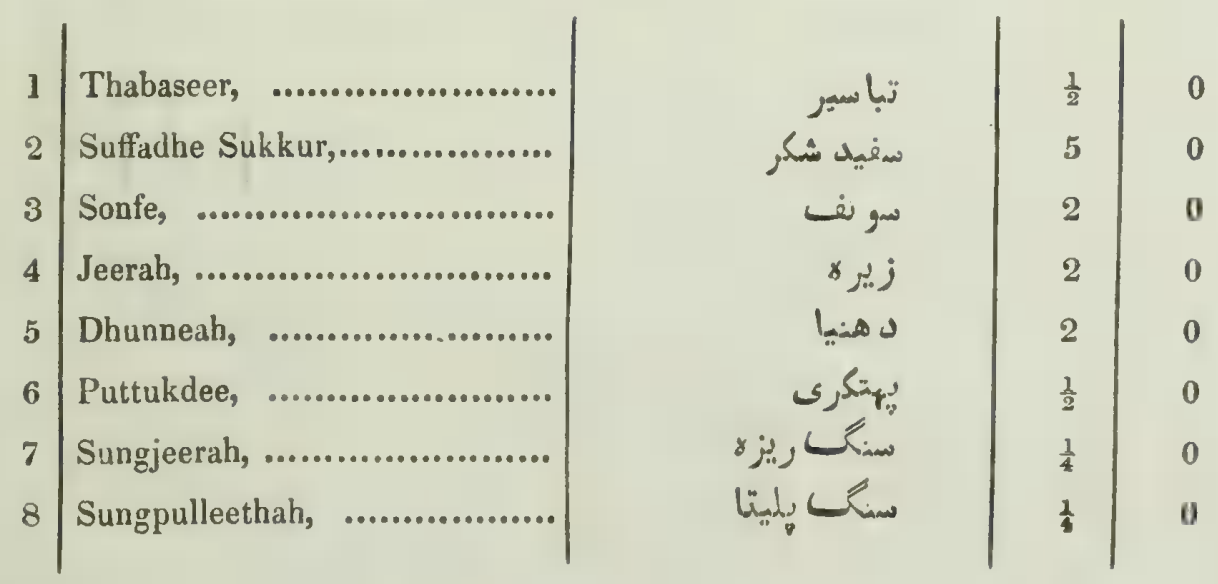

The substances to be finely pulverized and added to as much butter as will form it into a mass; then divide into boluses of size of a lime and give one every morning. 
ZOOLAAB-KA MURZ.

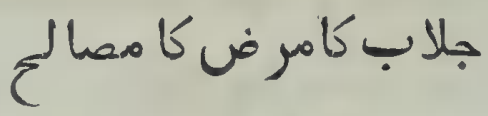

MUSSAL No. 1.

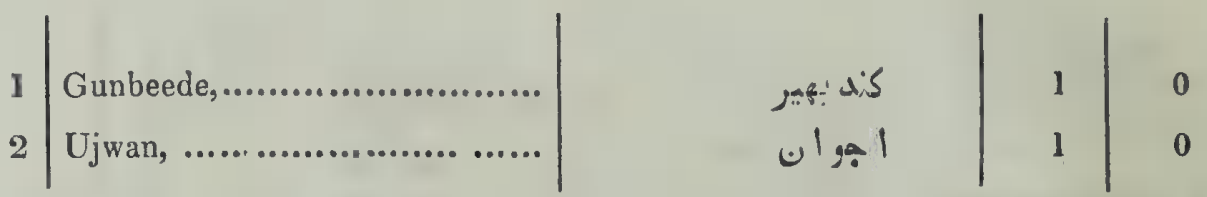

The above to be boiled in two seers of water and reduced to one seer, then give to animal. These substances my sometimes in this case act as a purgative.

MUSSAL No. 2.

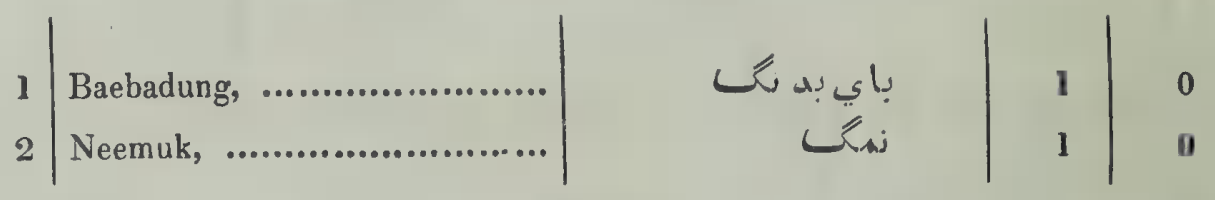

These to be boiled with two seers of water till reduced to one seer and then give to animal-should this act very violently on the bowels give one seer of Rice, boiled, with some butter-milk.

MUSSAL No. 3.

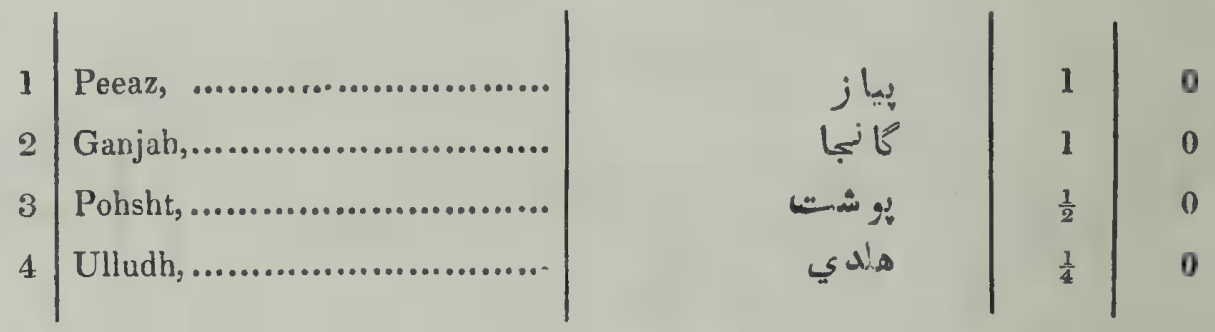

These to be well pounded together and given.

\section{PHUDMOOTE.}

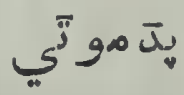

MUSSAL No. 1.

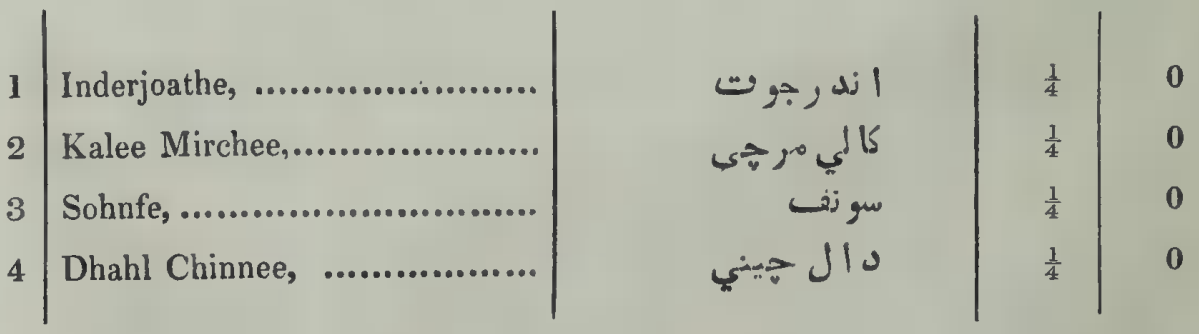

These to be finely pulverized, then added one seer of water and give once daily till relieved. 


\section{DHUNDEE-KA MURZ.}

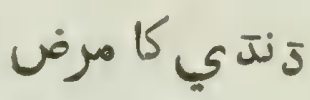

MUSSAL No. 1.

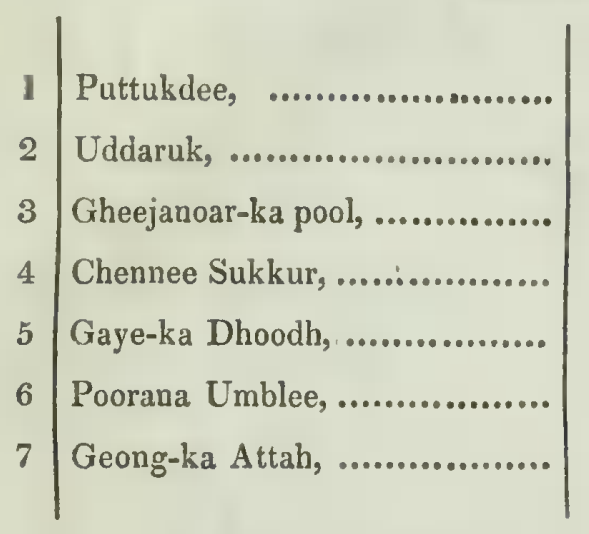

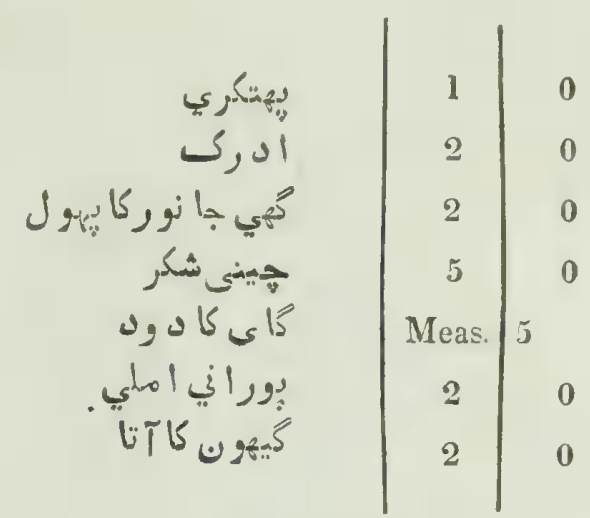

Nos. 1, 2, 3 and 6 to be well pounded together; Nos. 4 and 7 with No. 5 to be added, then heated to a mass; which divide into boluses of size of an Orange, and give one morning and evening for three successive days.

Give the following if the above prove inefficacious.

No. 1.

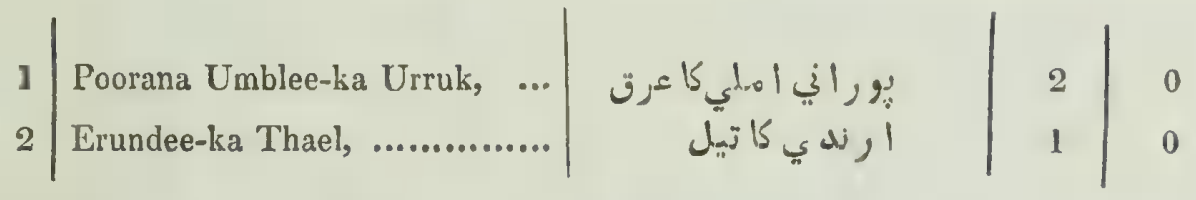

To be well mixed together.

ANOTHER No. 2.

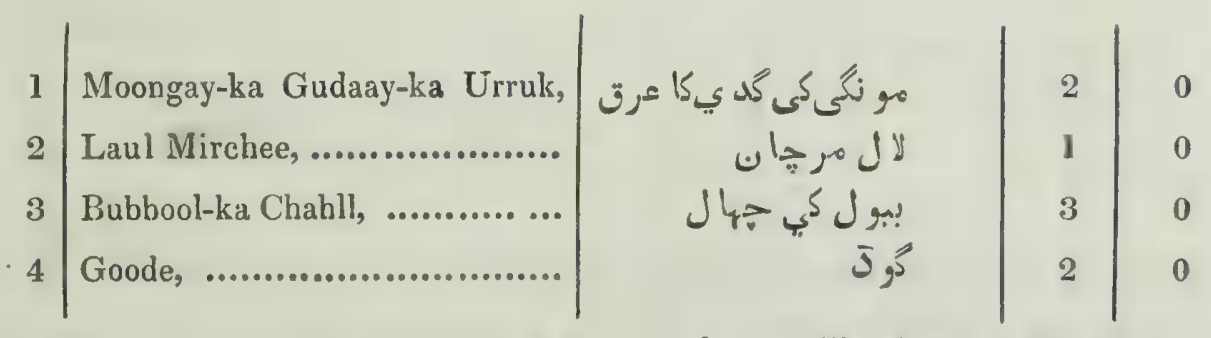

Nos. 2,3 and 4 to be boiled with 4 seers of water till reduced to $\frac{3}{4}$ th of a seer, then add No. 1 and give to animal.

ANOTHER NU. 3.
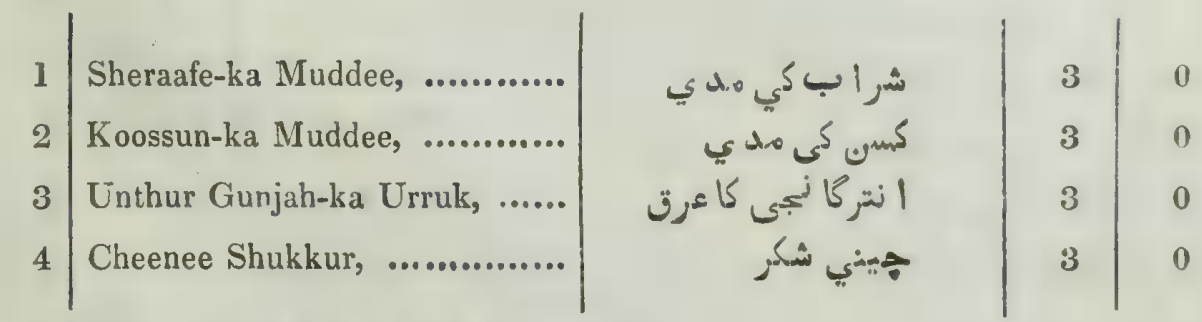

To be well mixed and given to animal. 


\section{ANOTHER No. 4.}

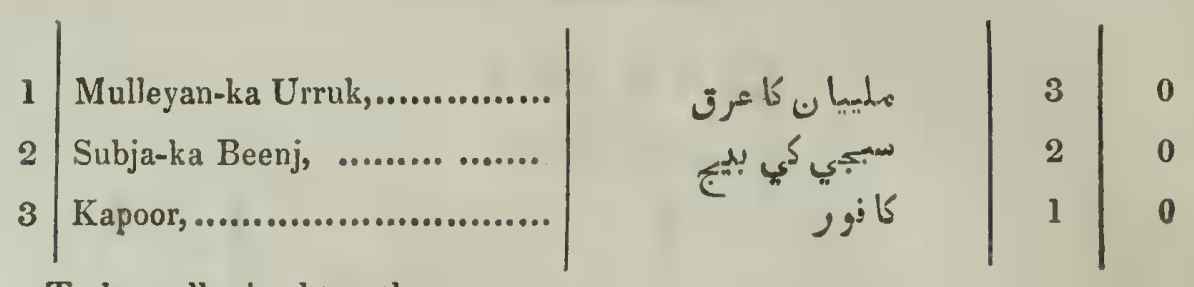

To be well mixed together.

\section{UDDHARUNG.}

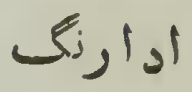

MUSSAL No. 1.
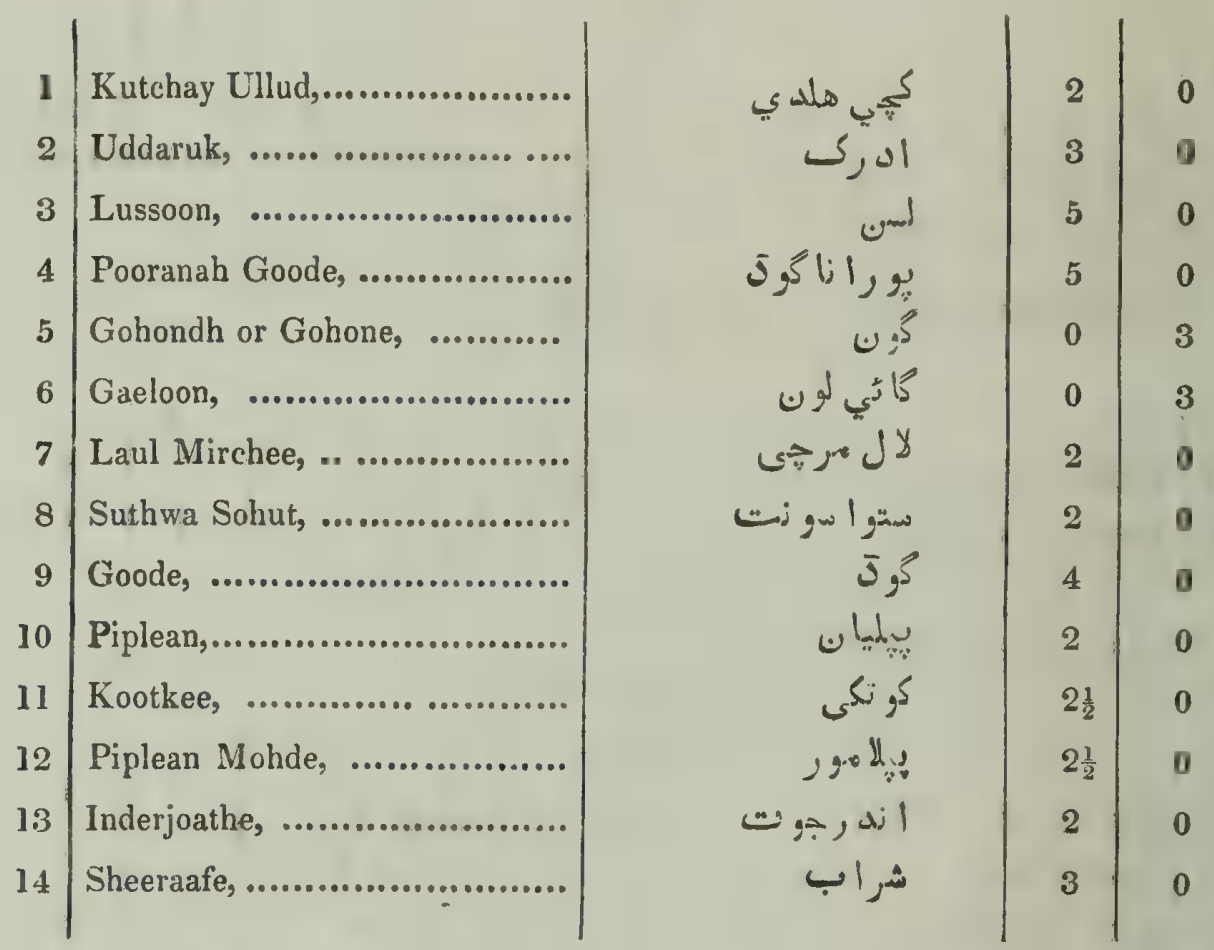

The substances to be finely pulverized, then add the Arrack and divide into three parts-one of which give every morning.

NAHASS, OR SNUFF.

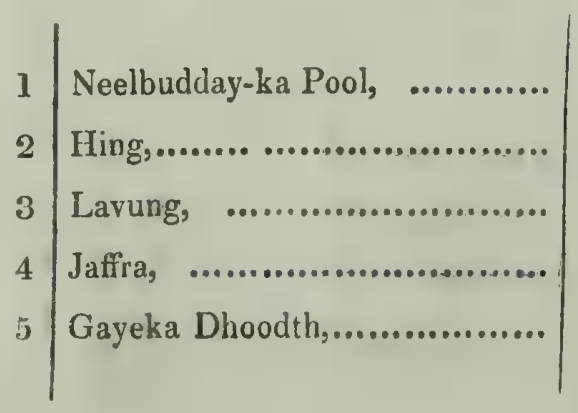

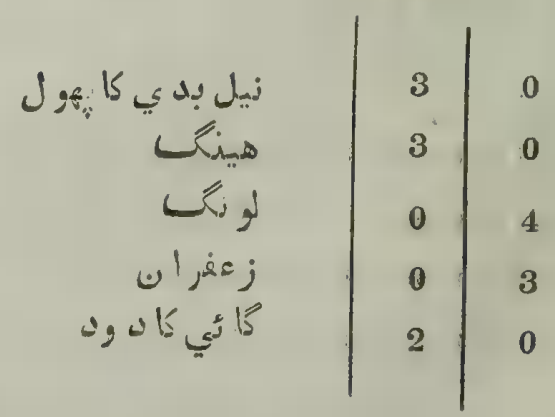


The substances to be finely pulverized and added to the milk, then boil down to $\frac{1}{4}$ seer, afterwards strain and pour into nostrils. The substances to be again boiled with the same quantity of milk and given internally.

\section{EAKUD, OR GAROOSH.}

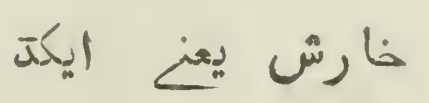

\section{EMBROCATION.}
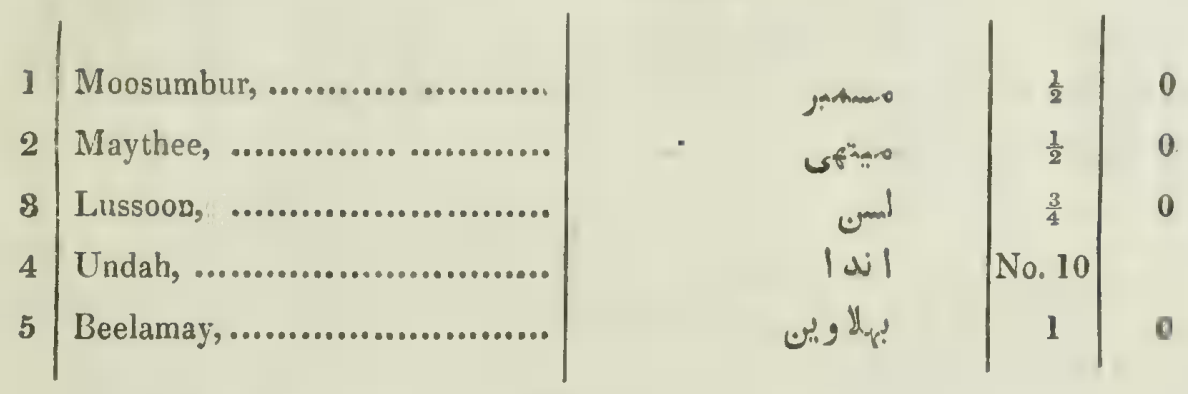

Nos. 1, 2, and 3 to be finely powdered. The white of the Eggs to be then added -afterwards add the No. 5; mix well and apply to the affected part. A heated bratty to be then held near the part until it is dried.

\section{MUSSAL TO BE GIVEN INTERNALLY.}
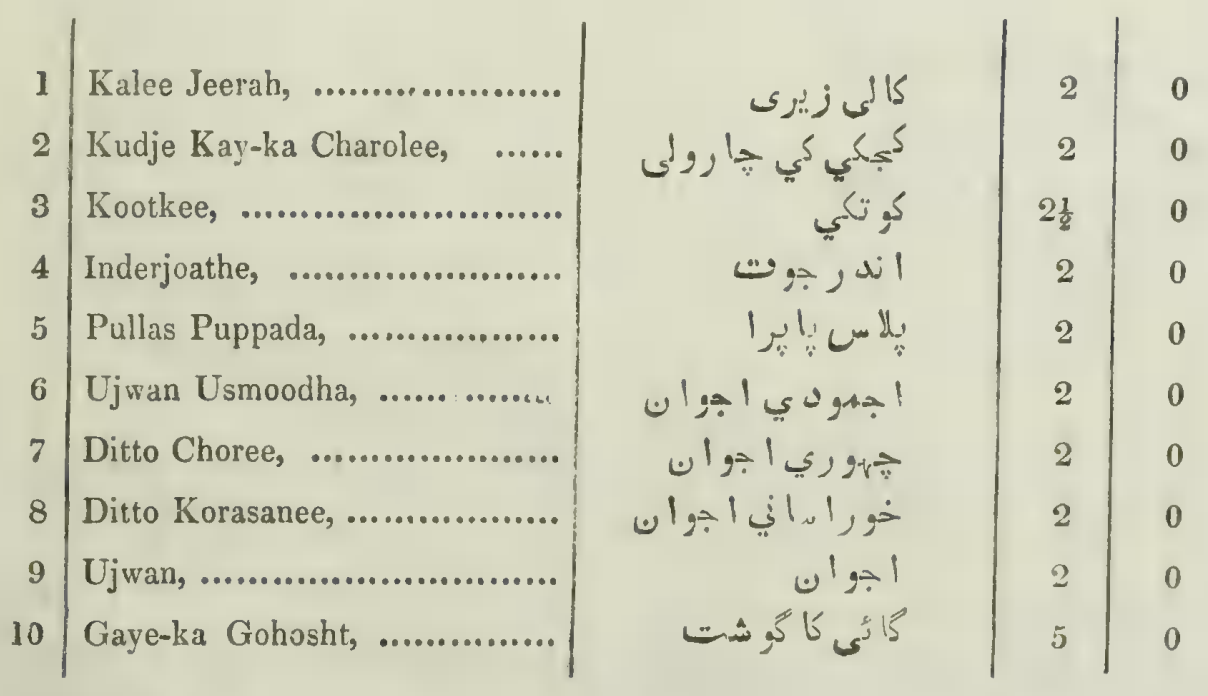

The above to be well pounded and No. 10 to be cut in small pieces, then pound togetber, of which give a handful morning and evening. If No. 10 is not procurable add Country Arrack. 


\section{RUNDUK.}

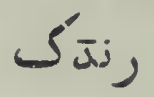

EMBROCATION.
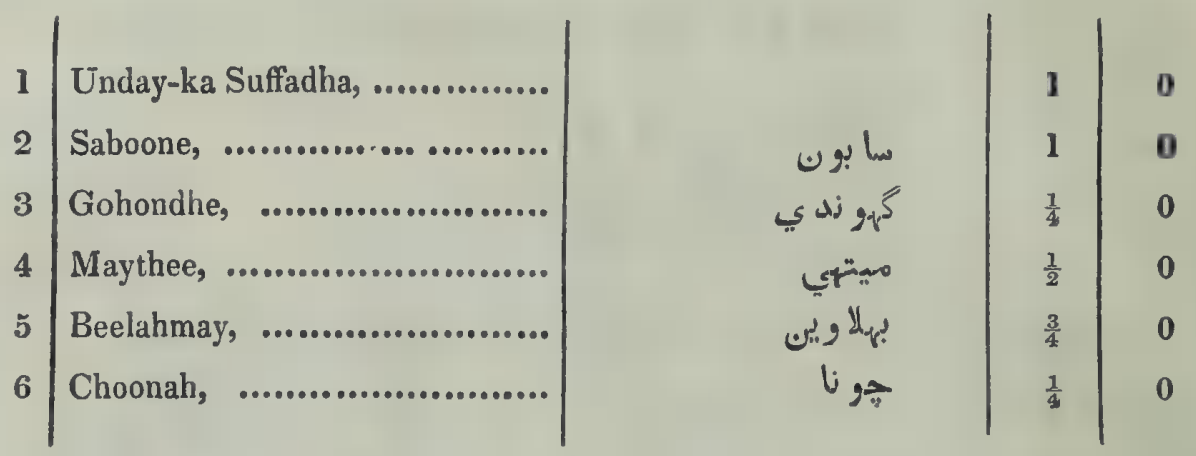

The whole to be well pounded, adding a sufficient quantity of water to form into an embrocation and apply to the affected parts. A heated Cow's dung to be held near until it is dried.

\section{BALE NUR.}

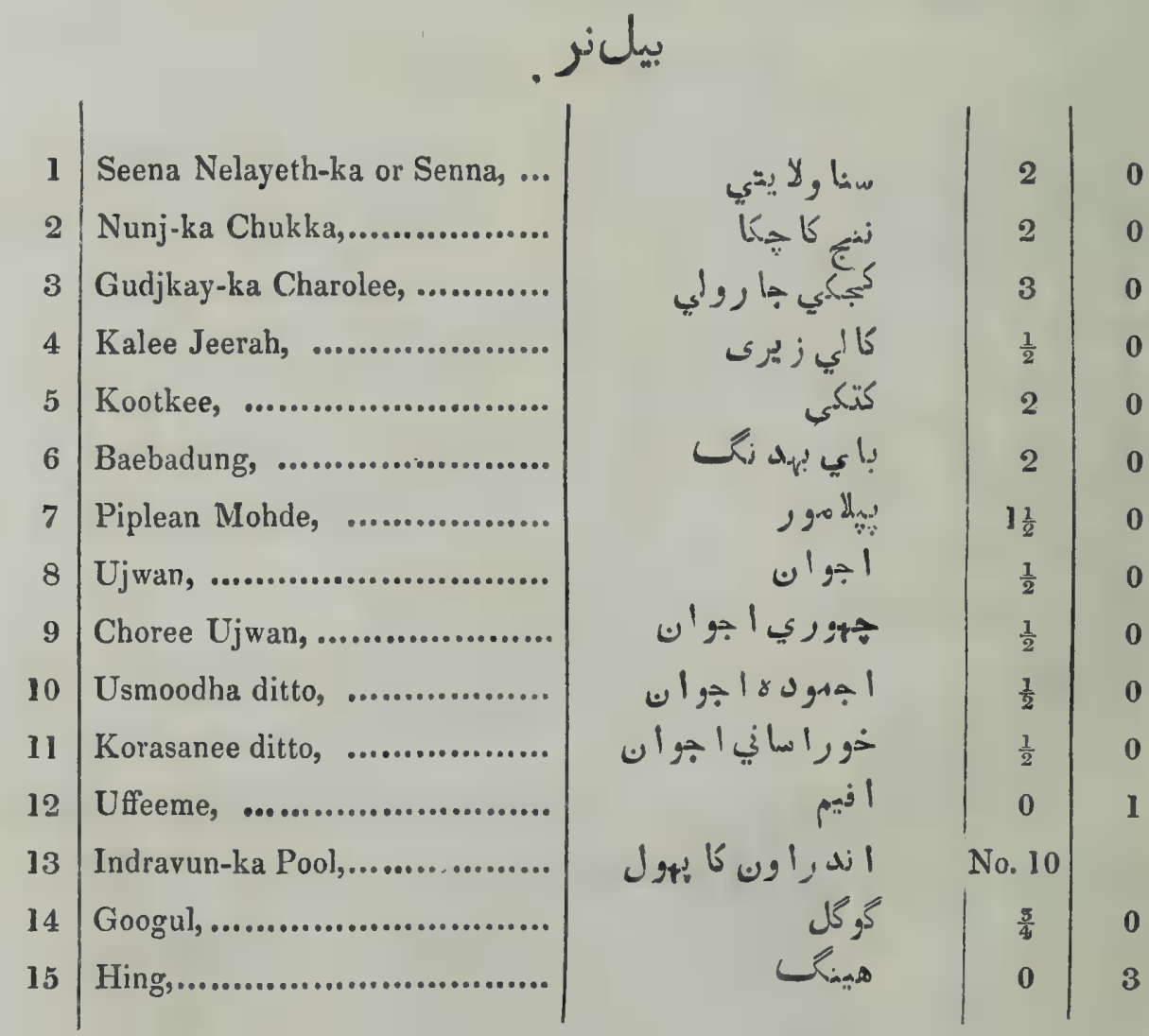

The substances to be finely powdered and mixed in a bottle water to form a mass, then divide into boluses of size of an orange-give one every morning. 


\section{BALE MAHDHA.}
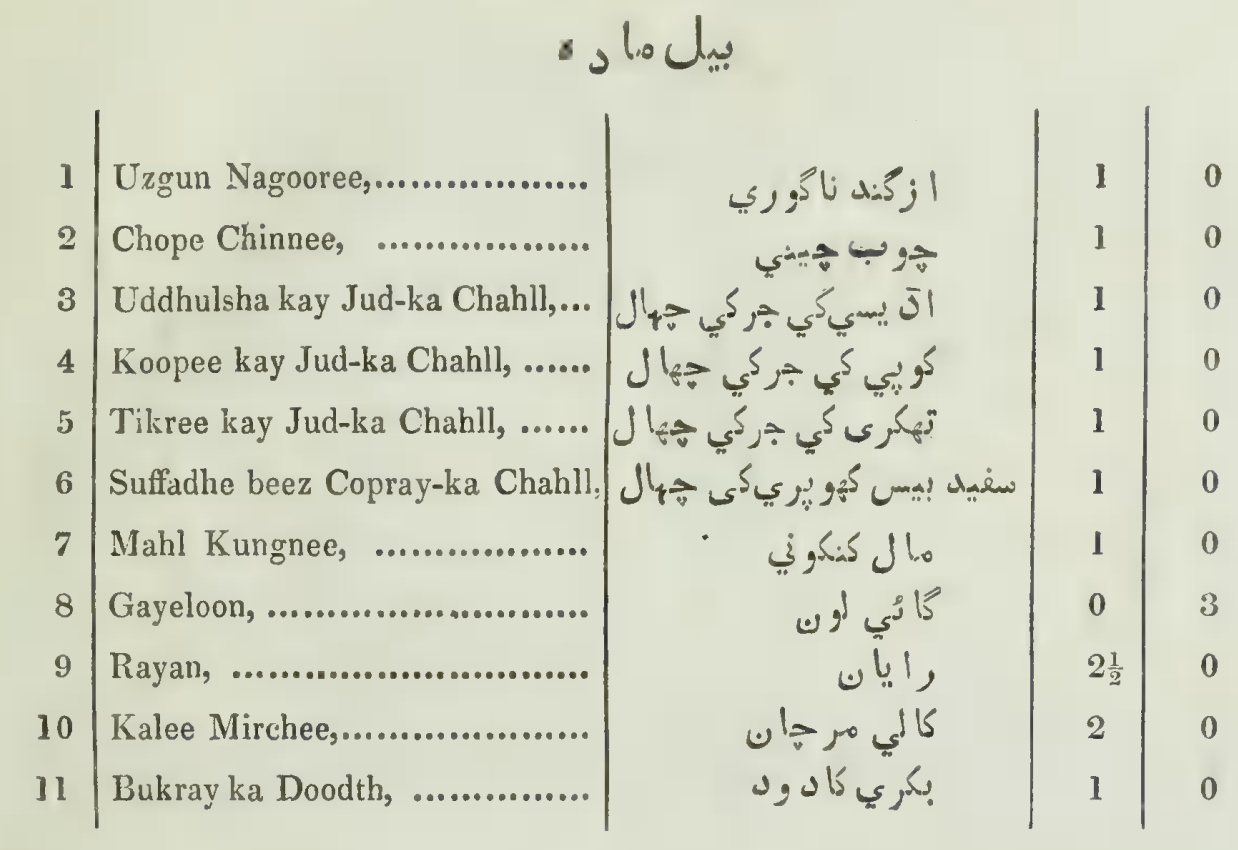

The above to be well pounded and No. 11 to be then added with one seer of Arrack. This mixture to be then buried under earth for $\mathbf{4 0}$ days, and afterwards taken out and divided into boluses of size of an Orange, and give one every morning.

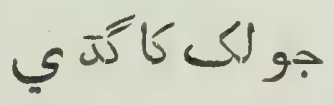

\section{JHOLLUCK-KA GUDDAY.}

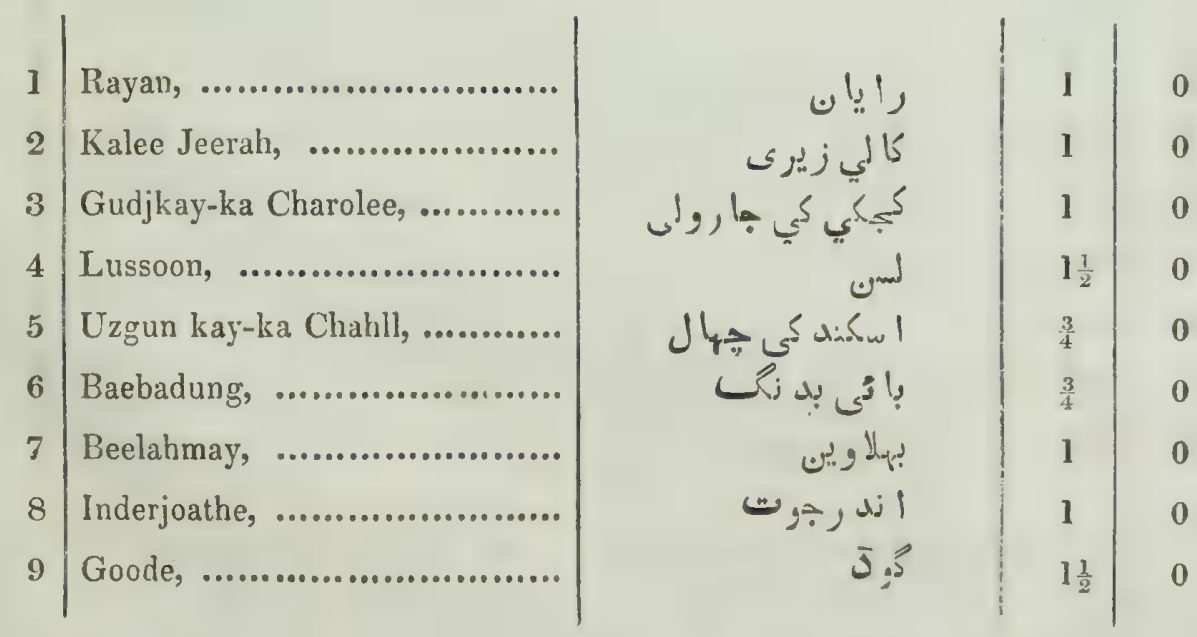

The substances to be pounded together and divided into boluses of size of a large lime, one of which to be given every morning. 


\section{SURDHEE.}

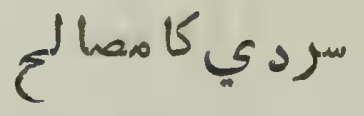

MUSSAL No. 1.
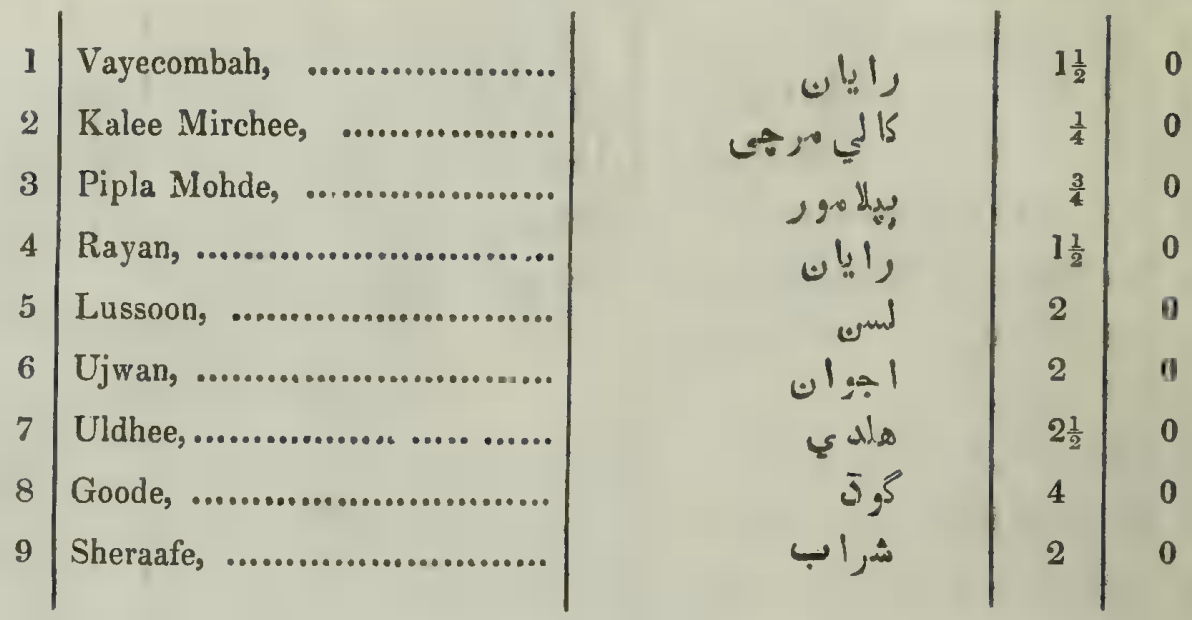

The substances to be pounded together and mixed with the Sheraaie; then divide into three parts, of which give one every morning.

\section{DHOOBLA, OR LAAGAAR.}
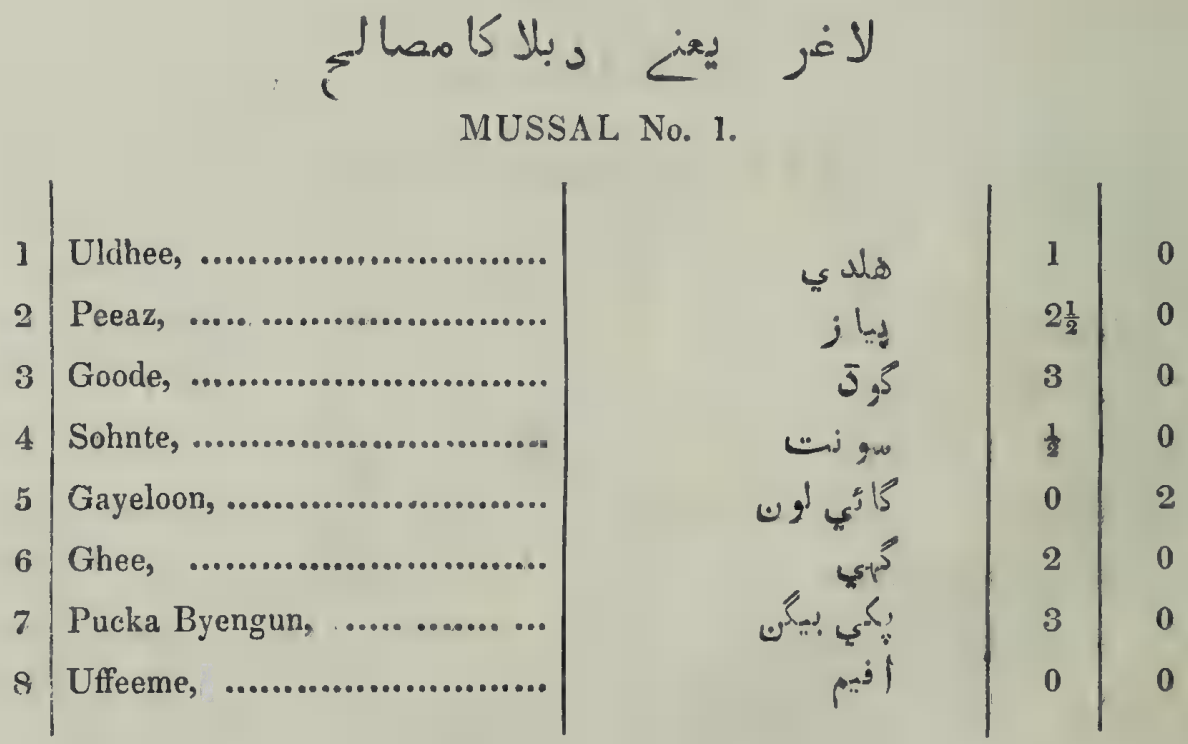

The substances to be finely pulverized and added to No. 6, and divide into bohuses of size of a lime, of which give one every morning. 


\section{$(51)$}

\section{ANOTHER.}

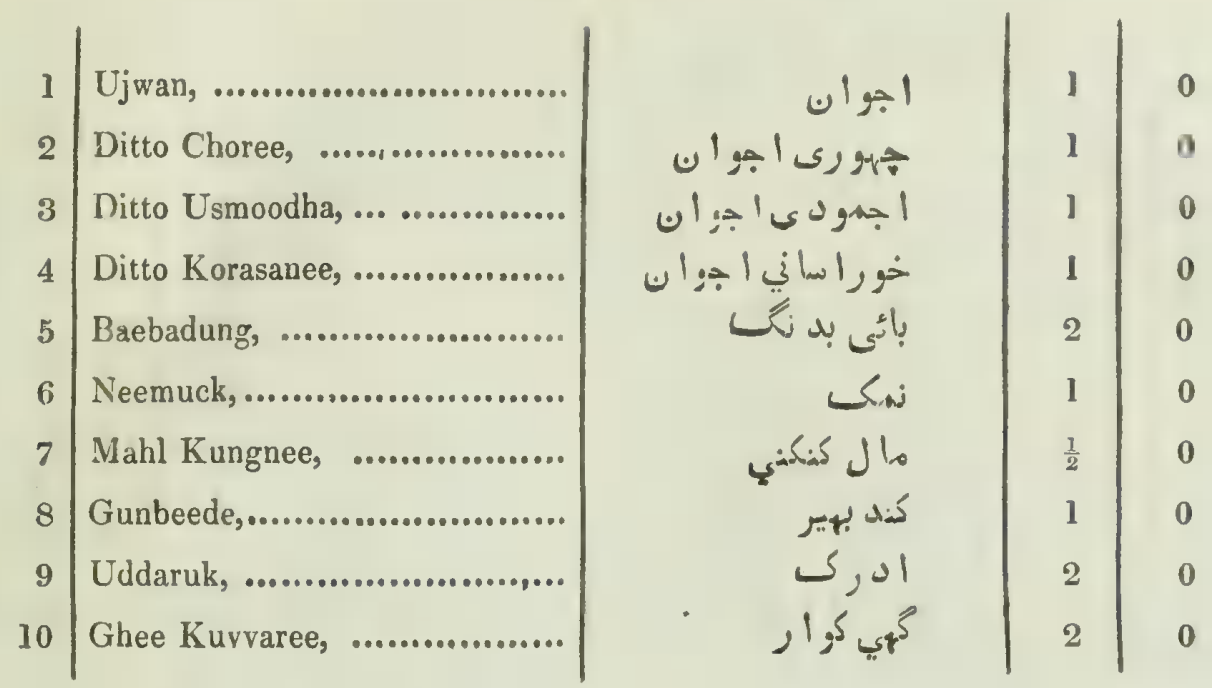

The whole to be well pounded, put into a pot, and buried under earth for 14 days - then take out and divide into boluses of size of a lime. Give one every morning.

\section{KAAREESH.}

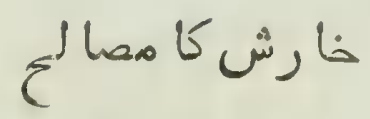

\section{ITCH OINTMENT.}
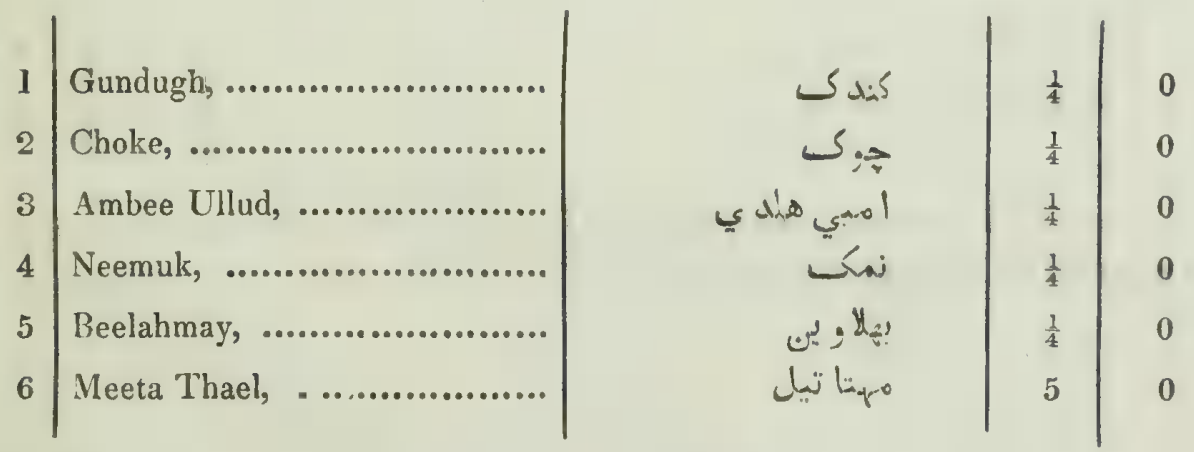

Nos. 1, 2, 3 and 4 to be finely pulverized separately. The marking nuts to be broken and boiled with the oil for a short time; after which throw away the nuts and add to the oil the powdered ingredients, mix, then rub over body of animal. 


\section{$(52)$}

MAHANDHGEE-KA MUSSALA.

No. 1

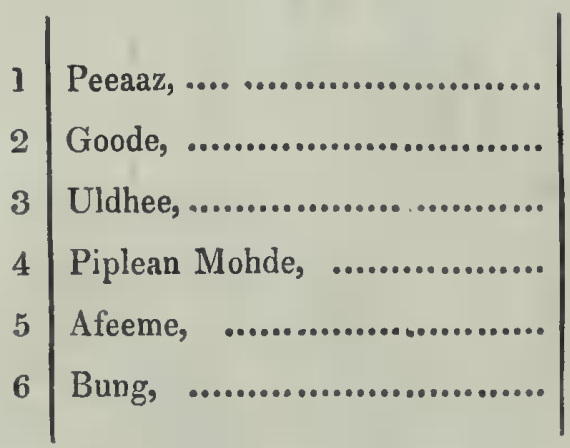

\begin{tabular}{|c|c} 
Seers. & Tolas. \\
2 & 0 \\
1 & 0 \\
1 & 0 \\
$\frac{1}{2}$ & 0 \\
0 & 1 \\
$\frac{1}{2}$ & 0
\end{tabular}

The above to be well pounded together, and either given at once, or at two different times.

ANOTHER No. 2.

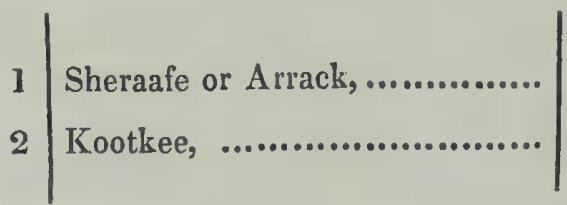

Bottle one.

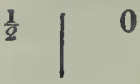

No. 2 to be finely pulverized and added to the Arrack and given at once. To be repeated, if necessary, the following day.

ANOTHER No. 3.
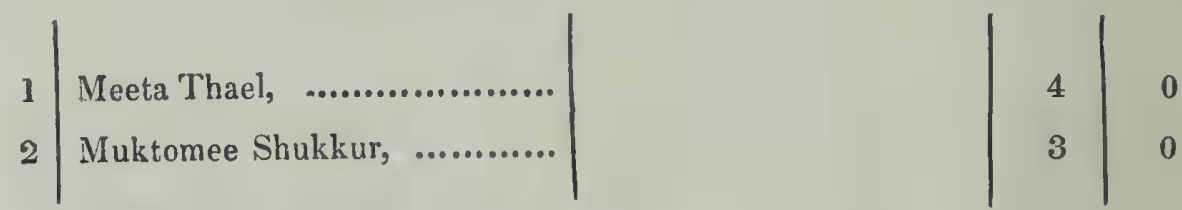

The both ingredients to be well mixed together and given for a dose-and to be repeated for three successive days. 


\section{PART F O R TH.}

\section{A GENERAL VIEIV OF THE ANATOMY OF THE CAMEL.}

As the Camel differs little in its general organization from the Horse, and as only so much of its Anatomy is intended here to be given as will meet the practical object of a guide in the treatment of diseases of its organs, little under this head need be advanced. Indeed, the osseous system or Skeleton, and the Sanguiferous, appear to be all that it is practically useful to allude to. The former, as affording land-marks of the relative position of organs-the latter in reference to the operation of bleeding.

\section{OF THE OSSEOUS SYSTEM.}

Table lst is a sketch of the Skeleton of a Camel fitted up at Hoonsoor under my superintendence, with the view to convey some idea of the structure of the animal to the Serwans.

1. The cranium and upper and lower jaws. In the upper jaw there are no front incisor teeth. There are two canine teeth and five grinders on each side. In the under jaw there are six front or incisor teeth-two canine on either side and five grinders.

B. The bones or vertebræ of the neck, of which there are seven.

C. Vertebræ of trunk and loins, of which there are nineteen.

D. Ribs, of which there are twelve on each side.

$E$. The shoulder blade. $F$. The Humerus, or arm bone. $G$. The bone of the fore-arm. H. The bones of the carpus or wrist of which there are seven in each fore-limb. I. The metatarsus or carpal bones. $J$. The phalanges, of which there are six arranged in the two parallel views. At $K$. are four semilunar shaped bones.

$L$. The rump-bone, terminated by $M$. the bones of the tail.

N. The haunch bones, or side bones of the pelvis.

$O$. The thigh bone.

$P$. The tibia or bone of the leg.

Q. The bones of the tarsus, of which there are as in the fore limb seven. 


\title{
( $54, \quad)$
}

R. The metatarsal bone.

$S$. The phalanges or feet bones. $T$. the four hinder bones of the feet of which in all as in the forefeet there are ten bones.

U. The knee pan.

\section{SANGUIFEROUS SYSTEM OF THE CAMEL.}

Different from the sanguiferous system of the Elephant that of the Camel, at least in the venous department, is very capacious-large veins are to be seen extending longitudinally alongst lower part of trunk and in the neck; the jugular vein is between 2 inches to $2 \frac{1}{2}$ inches in diameter. But the pulsations of the arterial system is not distinct. No artery about head, neck or extremities is to be found possessing a distinct and easily recognizable pulse. The heart is to be felt, though not always distinctly beating, when pressure is made with the hand between top of forelegs in front of the chest. From several observations made there it would appear that the pulsations of the heart in a healthy subject amount to fifty-four in a minute.

\section{OPERATION OF BLEEDING.}

The large diameter and superficial site of the external jugular vein in neck renders the operation of bleeding one of very easy performance.

The animal is made to place itself in the couchant position. The forelegs are then secured as represented in Table $2 \mathrm{~d}$. A. to prevent the animal rising: then a rope moderately tight is put round neck as at $\mathrm{B}$. The jugular vein speedily swells, at the site most eligible for the incision. C. and is opened by means of a common horse phlegme, used in the same manner as for bleeding a Horse.

A gallon and a half of blood is a full bleeding, and in inflammatory cases that quantity should in the first instances be abstracted; afterwards a gallon, or only half may be drawn off according to the urgency of the individual case.

An animal brought to Hospital with a fractured humerus, or arm bone, (an incurable accident) was made the sabject of experiment to ascertain how much blood could be drawn off from the jugular vein before death would ensue. The animal lived a few hours after upwards of ninety pounds had been abstracted.

\section{W. GILCHRIST,}

\author{
Asst. Surgeon, P. C. D.
}

\footnotetext{
Hoonsoor, ?

16th November, 1842.
} 

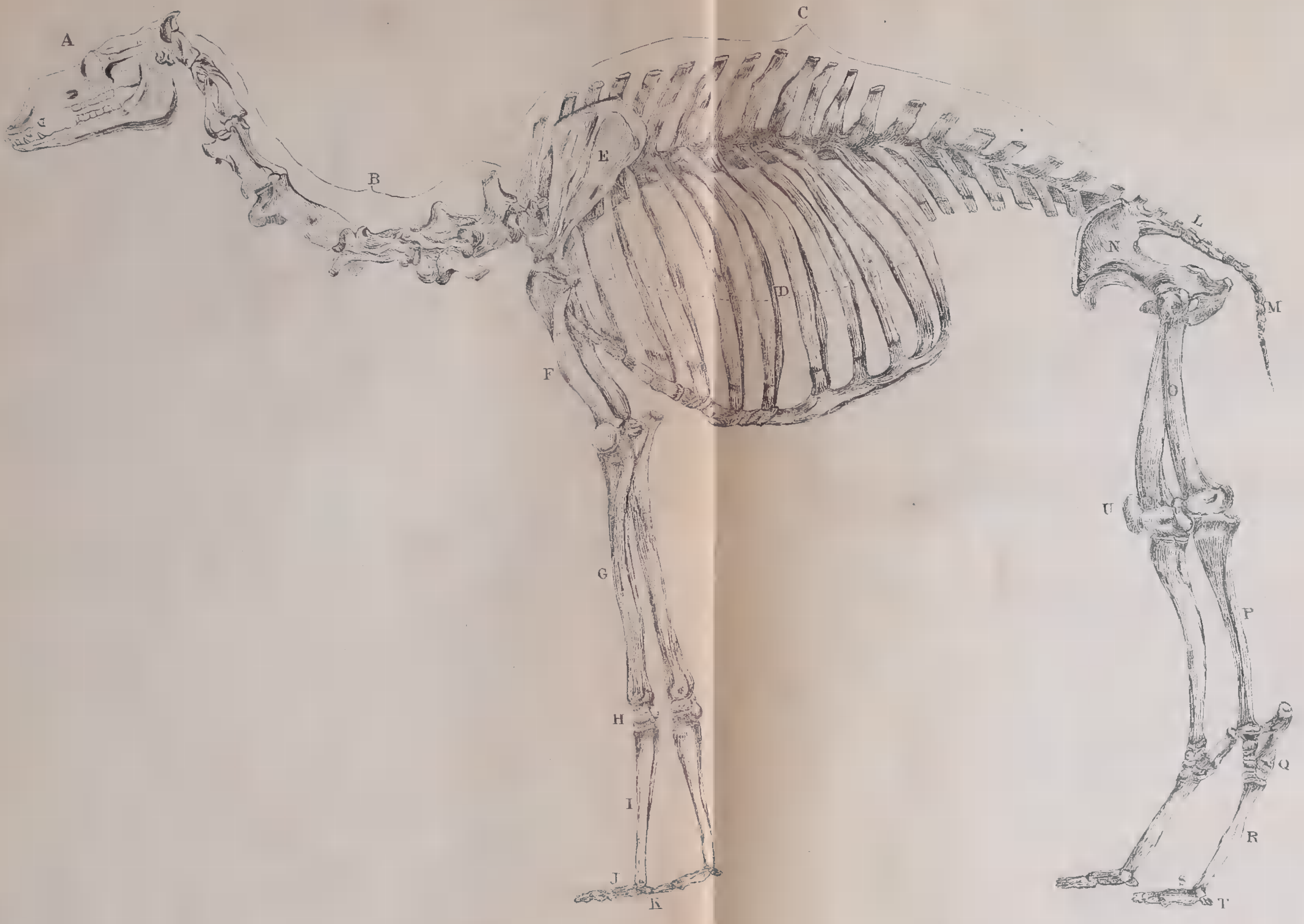

Fig: II

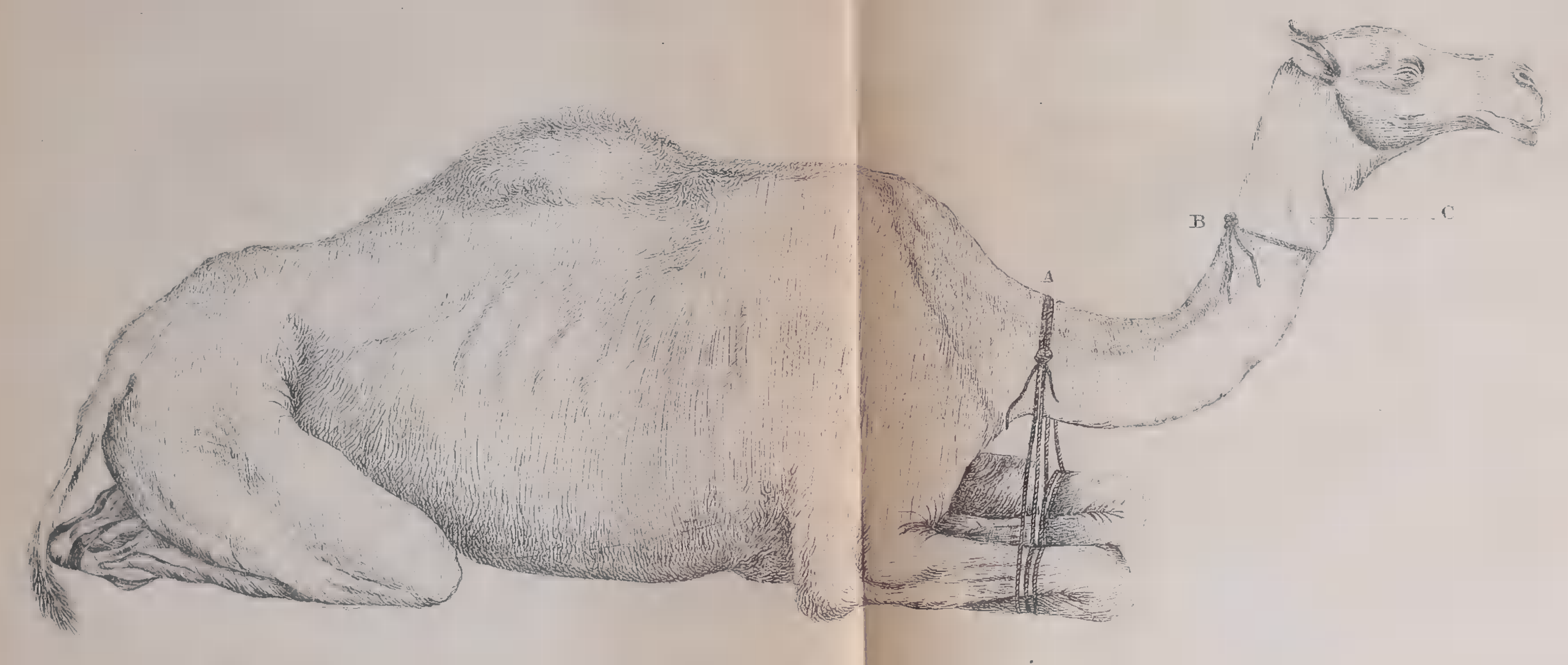







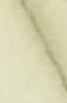






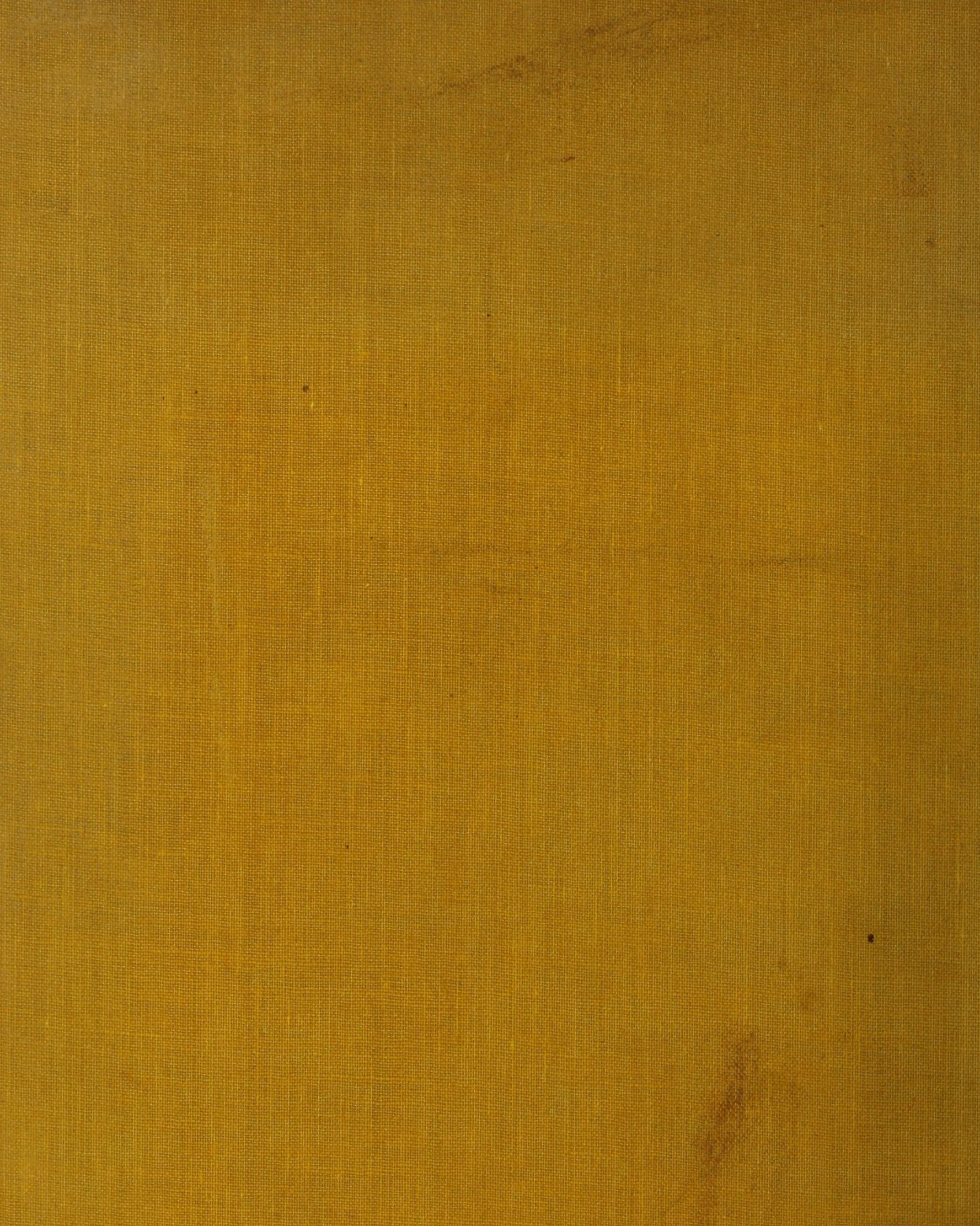

